Illinois State University

ISU ReD: Research and eData

Theses and Dissertations

$3-5-2017$

\title{
Changes in Anthropometric and Physiological Characteristics of Male Collegiate Rugby Union Players Throughout a Season
}

\author{
Edward Kyle Smith \\ Illinois State University, eksmith@ilstu.edu
}

Follow this and additional works at: https://ir.library.illinoisstate.edu/etd

Part of the Kinesiology Commons

\section{Recommended Citation}

Smith, Edward Kyle, "Changes in Anthropometric and Physiological Characteristics of Male Collegiate Rugby Union Players Throughout a Season" (2017). Theses and Dissertations. 712.

https://ir.library.illinoisstate.edu/etd/712

This Thesis is brought to you for free and open access by ISU ReD: Research and eData. It has been accepted for inclusion in Theses and Dissertations by an authorized administrator of ISU ReD: Research and eData. For more information, please contact ISUReD@ilstu.edu. 


\title{
CHANGES IN ANTHROPOMETRIC AND PHYSIOLOGICAL CHARACTERISTICS \\ OF MALE COLLEGIATE RUGBY UNION PLAYERS \\ THROUGHOUT A SEASON
}

\author{
Edward K. Smith
}

80 Pages

Rugby Union is a physically demanding sport requiring a variety of anthropometric and physiological characteristics to maximize performance. Factors such as muscular power, speed, agility, maximal aerobic power, mobility, and body composition all factor into player performance. PURPOSE: To determine changes in body composition, anthropometric and physiological characteristics of collegiate rugby union players throughout a competitive season. METHODS: Participants included 37 (20.3 \pm 1.5 years) men from a collegiate rugby club. Muscular power (vertical jump), speed (10m and 20m sprint), agility (L-drill), mobility (FMS active straight leg raise and shoulder mobility) maximal aerobic power (VO2 $2_{\text {peak }}$ via 20 m multistage shuttle run SR), height, body mass, fat mass (ADP), fat-free mass (ADP), and body fat levels (ADP and sum of 7 skinfolds (SKBF\%)) were assessed during the pre-season (PRE), midseason (MID), and post-season (POST). Training and match loads were estimated for each player by multiplying each player's rating of perceived of exertion (RPE: 6-20) by the amount of training/playing time. RESULTS: PRE, MID, and POST variables were compared using a repeated measures ANOVA $(p<.05)$. Paired-Samples T-Tests were used for post-hoc analysis to determine when the significant changes occurred $(p<.017)$. 


\begin{tabular}{ccccc}
\hline Assessment & Pre-Season & Mid-Season & Post-Season & $\begin{array}{c}\text { ANOVA } \\
p \text {-Value }\end{array}$ \\
\hline L-Drill Time (s) & $8.3621 \pm .32$ & $8.2321 \pm .36^{\mathrm{a}}$ & $\begin{array}{c}8.5493 \pm \\
0.42^{\mathrm{b}}\end{array}$ & $p=.005$ \\
\hline 10m Sprint Time (s) & $1.788 \pm 0.1$ & $1.892 \pm .063^{\mathrm{a}}$ & $1.91 \pm 0.08^{\mathrm{a}}$ & $p<.001$ \\
\hline 20m Sprint Time (s) & $3.118 \pm 0.15$ & $3.238 \pm 0.11^{\mathrm{a}}$ & $\begin{array}{c}3.2087 \pm \\
0.08^{\mathrm{a}}\end{array}$ & $p=.004$ \\
\hline VO2max (ml/kg/min.) & $45.86 \pm 4.37$ & $47.6 \pm 8.01$ & $41.25 \pm 6.4^{\mathrm{a}, \mathrm{b}}$ & $p=.001$ \\
\hline Triceps (mm) & $14.85 \pm 6.59$ & $13.22 \pm 6.9^{\mathrm{a}}$ & $12.59 \pm 6.4^{\mathrm{a}}$ & $p<.001$ \\
\hline Pectoral $(\mathrm{mm})$ & $14.96 \pm 7.4$ & $14.11 \pm 8.18$ & $13.33 \pm 7.35^{\mathrm{a}}$ & $p<.001$ \\
\hline Thigh $(\mathrm{mm})$ & $18.56 \pm 8.95$ & $17.19 \pm 8.27^{\mathrm{a}}$ & $15.7 \pm 8.24^{\mathrm{a}, \mathrm{b}}$ & $p<.001$ \\
\hline Calf $(\mathrm{mm})$ & $12.22 \pm 5.49$ & $11.04 \pm 4.82^{\mathrm{a}}$ & $9.81 \pm 4.74^{\mathrm{a}}$ & $p<.001$ \\
\hline Midaxillary $(\mathrm{mm})$ & $16.52 \pm 7.21$ & $14.67 \pm 8.52^{\mathrm{a}}$ & $13.81 \pm 7.35^{\mathrm{a}}$ & $p<.001$ \\
\hline Sum of 7-Sites (mm) & $127 \pm 52.43$ & $118.19 \pm 56.1^{\mathrm{a}}$ & $115.3 \pm$ & $p<.001$ \\
\hline Estimated Bd & $1.061 \pm .014$ & $1.0641 \pm .015^{\mathrm{a}}$ & $1.065 \pm .013^{\mathrm{a}}$ & $p<.001$ \\
\hline Estimated BF $(\%)$ & $16.6 \pm 6.21$ & $15.28 \pm 6.74^{\mathrm{a}}$ & $15.01 \pm 6.39^{\mathrm{a}}$ & $p<.001$ \\
\hline
\end{tabular}

a: Significantly different from Pre-Season, b: Significantly different from Mid-Season. (Mean \pm

SD). CONCLUSION: The majority of positive anthropometric and physiological adaptations

took place during the first half of the season when training was conditioning and skill focused.

Increased maximal aerobic power and agility may be due to participants becoming leaner and adapting to the conditioning performed during training. The accumulating training and match loads, decreased recovery times, and shift away from conditioning during training towards gamesimulation and team walkthroughs during MID to POST may have led to increasing levels of body fat and decreased fat-free mass, agility, speed, and maximal aerobic performance.

KEYWORDS: Anthropometry, Collegiate, Physiology, Rugby Union 


\section{CHANGES IN ANTHROPOMETRIC AND PHYSIOLOGICAL CHARACTERISTICS \\ OF MALE COLLEGIATE RUGBY UNION PLAYERS \\ THROUGHOUT A SEASON}

EDWARD K. SMITH

A Thesis Submitted in Partial Fulfillment of the Requirements for the Degree of

MASTER OF SCIENCE

School of Kinesiology and Recreation

ILLINOIS STATE UNIVERSITY 
(C) 2017 Edward K. Smith 


\title{
CHANGES IN ANTHROPOMETRIC AND PHYSIOLOGICAL CHARACTERISTICS OF MALE COLLEGIATE RUGBY UNION PLAYERS THROUGHOUT A SEASON
}

\author{
EDWARD K. SMITH
}

COMMITTEE MEMBERS:

David Q. Thomas, Chair

Daniel J. Dodd

Dale D. Brown

Kelly R. Laurson 


\section{ACKNOWLEDGMENTS}

I would like to thank my committee as well as Tyler Langosch, Jon Grimwood, and Nate Fillers for making this project possible. I also would like to thank all of those who participated in this project and my parents for their continuous support.

E.K.S. 


\section{CONTENTS}

\section{Page}

ACKNOWLEDGMENTS

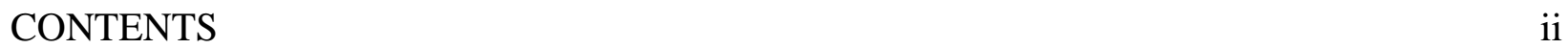

TABLES $\quad$ iv

FIGURES

$\begin{array}{ll}\text { CHAPTER } & 1\end{array}$

I. CHANGES IN ANTRHOPOMETRIC AND PHYSIOLOGICAL CHARACTERISTICS OF COLLEGIATE MALE RUGBY UNION

PLAYERS THROUGHOUT A COMPETITIVE SEASON 1

Introduction 1

Methods 3

Subjects and Procedures 3

$\begin{array}{ll}\text { Data/Statistical Analysis } & 7\end{array}$

$\begin{array}{lr}\text { Results } & 8\end{array}$

$\begin{array}{ll}\text { Discussion } & 12\end{array}$

$\begin{array}{ll}\text { Conclusion } & 18\end{array}$

$\begin{array}{ll}\text { Practical Applications } & 20\end{array}$

$\begin{array}{ll}\text { References } & 31\end{array}$

II. EXTENDED REVIEW OF LITERATURE 36

General Overview 36

Rugby Research

$\begin{array}{ll}\text { Summary } & 67\end{array}$

$\begin{array}{ll}\text { References } & 69\end{array}$ 
APPENDIX A: INITIAL MEETING QUESTIONAIRE

APPENDIX B: PHYSICAL ACTIVITY READINESS QUESTIONAIRE 


\section{TABLES}

Table

Page

1. Anthropometric changes from skinfold estimations

2. Anthropometric changes from ADP analysis

3. Results from battery of fitness tests

4. Monthly breakdown of training and match loads

5. Breakdown of estimated loads from the first and second-half of the season

6. Breakdown of match loads from first-half, second-half, and playoff matches

7. Training and match loads throughout the season 


\section{FIGURES}

Figure $\quad$ Page

1. Changes in thickness of skinfold sites 28

2. Estimation of body fat percentages via sum of 7-site skinfolds equation and ADP analysis

3. Changes in mobility 


\section{CHAPTER I:}

\section{CHANGES IN ANTHROPOMETRIC AND PHYSIOLOGICAL CHARACTERISTICS \\ OF COLLEGIATE MALE RUGBY UNION PLAYERS \\ THROUGHOUT A COMPETITIVE SEASON}

\section{Introduction}

Rugby union is a physically demanding sport broken up into two-forty-minute halves.

Each team consists of 23 players per roster with 15 players representing each side on the pitch at one time. Of the 15 players from each team, players can be broken-up into 2 broad categories of positions; Forwards and Backs. Each position on the pitch has a specific role as each member of the team must work together in order to outscore the opponent. Different positions have been found to have different anthropometric traits dictated by the positional role and physiological demands for that position. During a match, there are 2 main periods of play; a set-piece and open-play. Set pieces are used to restart play after a turnover and include events such as lineouts, scrums, and kickoffs. Open-play refers to the continuous periods of play between set-pieces. All players on the pitch regardless of position are expected to be involved rucking, tackling, running, kicking, and mauling. Scrums, rucks, line-outs, and mauls each involve more static exertion as each team fights for possession of the ball pushing against each other in an attempt to overpower their opponent.

Rugby union is a highly intermittent sport with short periods high-intensity activity followed by longer periods of low-intensity movements such as walking or jogging. While both GPS and time-motion analysis have found the total distances covered by rugby union players to be smaller compared to other sports such as soccer, much of the intensity can be accounted for 
by static exertion events such as scrums, lineouts, rucks, and mauls. Overall, forwards have been found to spend more time in static exertion, experience more collisions, make more tackles, and overall longer time performing high-intensity activities. Forwards have been reported to have experience higher levels of blood lactate accumulation and work at a higher percentage of maximum heart rate for a longer period of time than backs $(31,55)$. Backs have been found to spend more time running at high speeds, cover more distance per match, undergo more velocity changes, reach higher peak velocities, and have more time to recover from high-intensity bouts of exercise $(31,55)$.

Following the professionalization of rugby union in 1995, both forwards and backs have been getting taller, heavier, and leaner $(39,42)$. Many factors contributed to these changes such as dietary and conditioning interventions via full-time integrated nutritional and strength and conditioning staffs. Professional players also have more time dedicated towards improving performance as they would be less likely have a full-time paying career in addition to their practice and competitions $(39,42)$.

Previous research has found that over the course of the season, several changes in anthropometric and physiological factors may occur $(21,28)$. Several researchers have found that fat-mass decreases from pre-season to mid-season, but increases from mid-season to post-season $(21,25)$. It has been hypothesized that these changes may be due to increased conditioning loads earlier in the season when teams are looking to increase levels of fitness (21). Later, as the season progresses and teams fight to make a playoff-run, a decrease in conditioning loads is likely as the focus of training shifts from physical conditioning to match strategy and recovery from previous matches played (21). To date, no study has specifically measured changes in anthropometric and physiological characteristics such as body mass, fat-mass, fat-free-mass, 
height, sum of skinfolds, speed, aerobic and anaerobic power, agility, and mobility in American collegiate rugby union players over the course of a competitive season. To the authors' knowledge, only one study focusing on international rugby union players and one study on amateur rugby league players have measured changes in both anthropometric and physiological variables over the course of a competitive season $(21,28)$. Overall, even less research has focused on American collegiate rugby. Only one study focusing on a Division I American collegiate rugby union team has been identified (32).

The aim of this research was to determine if any changes in body composition or physiological factors such as speed, agility, mobility, muscular power, and aerobic power improve or decrease throughout the course of a competitive season. Members of a Division II American university rugby club were observed throughout the course of the 2016 fall season. Participants voluntarily completed a battery of fitness tests, skinfolds, and air displacement plethysmography (ADP) approximately 1-week prior to match-play, halfway during the regular season, and 1-week after the final match is played. It has been suggested that collegiate athletes may have a greater chance of experiencing more positive physiological adaptations throughout a season compared to professional players due to professional players being more likely to have a higher training status, thus being closer to the training threshold (23).

\section{Methods}

Subjects and Procedures: The study utilized a repeated-measures design subjecting volunteers to the same anthropometric and physiological assessments approximately 1-week prior to the competitive season (pre-season), at mid-season, and roughly 1-week following the completion of the fall campaign. Due to the contributing club advancing deep into the Division II playoffs, 
there were 4.5 weeks between the pre-season and mid-season data collection periods and 7.5 weeks between the mid-season and post-season data collection periods.

Participants consisting of 37 male collegiate rugby union players volunteers $(20.3 \pm 1.5$ years) were put through a battery of fitness tests as well as two forms of body composition assessment. Twenty-eight subjects completed the pre-season, mid-season, and post-season data collections while 9 additional subjects were recruited and partook in the mid-season and postseason collection sessions. All participants were recruited from the same Midwestern Division II collegiate rugby team and completed the same body composition and battery of fitness tests. The participating team's season began on September $17^{\text {th }}$ and concluded November $20^{\text {th }}$. The preseason data collection period took place between September $2^{\text {nd }}$ and September $16^{\text {th }}$ with the Mid-season data collected taking place roughly 4.5 weeks later from October $5^{\text {th }}$ to October 14 th. The post-season data collection was completed from November $29^{\text {th }}$ to December 2 nd. Prior to participation within the study, each subject filled out a Physical Activity Readiness Questionnaire, Rugby Participation Questionnaire, and Informed Consent to make it known that they were currently uninjured and able to safely participate in the study.

All subjects underwent anthropometric evaluation within a 1-week period at a time that suited their schedule. Fat-mass and fat-free-mass for each participant were estimated via an ADP analysis. The BODPOD quantifies the amount of air displaced by a human and compares their volume to the volume of when the chamber is empty and when there is a calibration cylinder with a known volume of 50L. Before subjects entered the BODPOD, their heights were taken via a wall-mounted stadiometer (SECA, Chino, CA) and recorded to the nearest tenth of a centimeter. Body mass was assessed as part of the standard BODPOD procedure and was recorded in kilograms. To ensure the most accurate estimations possible, subjects were asked to 
wear fitted compression shorts and a compression cap to avoid excess air being trapped within their clothing. All jewelry was removed and subjects refrained from eating, drinking, or exercising 3-hours prior to their assessment.

In order to estimate possible regional fat-mass deviations, 9-skinfold sites were measured using a Lange caliper (Santa Cruz, CA, Beta Technology Inc.). The 9-sites measured included the pectoral, triceps, biceps, abdominal, suprailliac, subscapular, midaxillary, thigh and calf. All measurements were taken by the same 2 researchers. Both researchers are experienced in taking skinfold measurements and are employed within the exercise physiology laboratory. In order to maintain consistency, a record was kept of which researcher performed each skinfold assessment. However, due to scheduling conflicts, the same researcher was not always available to measure participants for all 3 assessments. While 9 sites were measured, the sum of 7 -sites equation was used to estimate fat-mass for each individual (30).

The battery of fitness tests took place the following the week of anthropometric testing. Groups of no more than 15-20 participants were brought into the Physical Education Instructional Gymnasium. All physiological testing sessions took place in the same room and on the same surface. Each group was led through a 5-minute dynamic warm-up led by the research team. Warm-up exercises included high-knees, walking lunges, butt-kickers, lateral shuffles, walking straight leg raises, quad-pulls, and 50-75\% sprints. Once each participant was warmedup, the whole group was split into a smaller faction. Unit A performed the Active Straight Leg Raise Functional Movement Screen (FMS) component test followed by the vertical jump. Unit B completed the Shoulder Mobility FMS component test prior to the L-drill. Once both units completed both assessments, they switched stations to complete the other 2 assessments. Once 
the 4 initial assessments were finished, Units A and B combined to perform the $10 \mathrm{~m}$ and $20 \mathrm{~m}$ sprints. The fitness battery concluded with the $20 \mathrm{~m}$ multi-stage shuttle-run as one large group. The two Functional Movement Screening component tests were used to try and identify any variation in players' hamstring and shoulder mobility throughout the season. The FMS Active Straight Leg Raise has been reported to be the most effective FMS component for predicting an injury in rugby union players (49). Those who scored 2 or lower are 9.4 times more likely to sustain an injury (49). While there was no such finding for the Shoulder Mobility FMS, shoulder injuries are quite common among rugby players as each player will be involved in some variation of physical contact throughout a match. The guidelines provided by the FMS instruction manual were used throughout the testing process. Each participant completed each FMS component test twice with the best score being recorded. Due to scheduling conflicts, different researchers performed the FMS assessments leaving room for inter-testing variability.

Power is an essential proponent of rugby union. A Vertec (Sport Imports, Hilliard, OH) was utilized to assess each individual's vertical max jump. Players were first asked to walk underneath the Vertec looking straight ahead with their dominant arm held upwards and their shoulders square to measure their reach. Next, each participant was instructed to jump upwards as high as they could and use their hand to move the target vanes indicating how high they had jumped. A single-file line was formed and each subject had 2 attempts to jump up as high as he could without any instruction of jumping technique. A similar counter-movement jump test has been used previously to assess muscular power in amateur and professional rugby league players respectively $(21,53)$.

An L-drill was completed twice by each player to assess agility. Three cones were set-up in the shape of an "L" with each cone being 5 yards apart. A FITLIGHT trainer system (Fitlight 
Corp., Ontario, Canada) was used in order to measure time to the nearest hundredth of a second for each trial. A timing light was placed on the first cone and a cone adjacent to the starting cone where the players finished. The clock both stopped and started as soon as the player crossed the paths of each light. Three cones were set-up with one at the starting line, $10 \mathrm{~m}$ mark, and $20 \mathrm{~m}$ mark. Each cone had a FITLIGHT timing light attached to it to record the time to the nearest hundredth of a second for each participant. Players were instructed to run as fast as they could past the final cone to ensure they maintained their maximum speed the entire $20 \mathrm{~m}$.

Each player's VO2max was estimated via a 20m Multi-Stage Shuttle-Run. This assessment required players to run a $20 \mathrm{~m}$ distance at a pace dictated by a recorded compact disc. Each player was instructed to keep following along with the voice until volitional failure. Once completed, the age of each subject and speed of the level they stopped were entered into a validated equation to estimate their VO2max (34).

Training and match loads were estimated for each subject by multiplying the number of minutes each subject participated in a training session or match by a self-reported Rating of Perceived Exertion (RPE). Participants were asked to rate how intense each training session or match was on a scale of 6-20 with 6 being compared to as if the participant was lying in bed or resting and 20 being maximal exertion.

Data/Statistical Analysis: A repeated-measure analysis of variance (ANOVA) was used to quantify changes for each variable throughout the season comparing scores for each variable during the pre-season, mid-season, and post-season. If a significant result was found via the repeated measures ANOVA $(\mathrm{p}<.05)$, a paired t-Test post hoc analysis was used for that variable to determine at what point of the season the significant changes occurred. In order to determine at which point of the season the significant changes occurred, the initial alpha $(p<.05)$ was 
divided by 3 for the paired $t$-Tests $(p<.017)$ as 3 points of the season (pre-season, mid-season, and post-season) were being compared. All statistical analyses were conducted using SPSS Version 23 (SPSS Inc., Chicago, IL).

\section{Results}

Over the course of the 3-month Fall campaign, several anthropometric adaptations were found to exist for sum of 7-skinfolds, estimated body density, estimated body fat percentage from skinfolds, and the thicknesses of the pectoral, triceps, midaxillary, thigh, and calf skinfolds sites. Conflicting results were found in regards to changes in player body composition. A oneway repeated measures analysis of variance was calculated comparing the estimated body fat percentage of each player during each testing period from both the ADP analysis and 7-site skinfolds equation. No significant results were found between any point of the season for the ADP results. However, players' sum of 7-skinfolds, estimated body density, and estimated body fat percentage from the 7-site skinfolds equation were each found to significantly change $(\mathrm{F}(2,52)=10.383, \mathrm{p}<.001,(\mathrm{~F}(2,52)=12.44, \mathrm{p}<.001$, and $(\mathrm{F}(2,52)=12.25, \mathrm{p}<.001$ respectively. In order to determine at which point of the season the significant changes occurred, a paired samples t-test was utilized for each variable. Since all 3 variables are related to each other, all changes occurred at the same points of the season. The sum of 7-skinfolds was found to significantly decrease from the pre-season $(M=127.59, \mathrm{SD}=52.43)$ to the mid-season $(\mathrm{M}=$ $118.19, \mathrm{SD}=56.1)(\mathrm{t}(26)=2.96, \mathrm{p}=.006)$ and again from the pre-season to the post-season $(\mathrm{M}$ $=115.3, \mathrm{SD}=51.02) \mathrm{t}(26)=4.406, \mathrm{p}<.001$. Players became significantly more dense from the pre-season $(\mathrm{M}=1.061, \mathrm{SD}=.014)$ to the mid-season $(\mathrm{M}=1.064, \mathrm{SD}=.015)(\mathrm{t}(26)=-3.545, \mathrm{p}=$ $.002)$ and again from the pre-season to the post-season $(\mathrm{M}=1.0647, \mathrm{SD}=.015)$ overall $\mathrm{t}(26)=-$ 
$4.346, \mathrm{p}<.001$. Following the same pattern, the estimated body fat of each player via the 7 -site skinfold equation significantly decreased from the pre-season $(\mathrm{M}=16.6, \mathrm{SD}=6.21)$ to the midseason $(\mathrm{M}=15.28, \mathrm{SD}=6.74) \mathrm{t}(26)=3.498, \mathrm{p}=.002$. Estimated body fat also ended up being significantly lower when comparing the pre-season to the post-season $(\mathrm{M}=15.032, \mathrm{SD}=6.4)$ $\mathrm{t}(26)=4.352, \mathrm{p}<.001$.

As for the specific skinfold sites, the pectoral site was found to be significantly changed throughout the season $(\mathrm{F}(2,52)=3.885, \mathrm{p}=.027$. A paired $\mathrm{t}$-test revealed that the decrease in pectoral thickness was significantly higher during the pre-season $(\mathrm{M}=14.96, \mathrm{SD}=7.4)$ compared to the post-season result $(\mathrm{M}=13.33, \mathrm{SD}=6.4) \mathrm{t}(26)=2.729, \mathrm{p}=.011$. Like the pectoral site, significant changes were found for the triceps $(F(2,52)=15.567, p<.001$, midaxillary $(\mathrm{F}(2,52)=13.791, \mathrm{p}<.001$, thigh $(\mathrm{F}(2,52)=20.775, \mathrm{p}<.001$, and calf $(\mathrm{F}(2,52)=$ $8.906, \mathrm{p}<.001$. Paired t-tests for each site revealed that significant decreases occurred during the first half of the season and when comparing the pre-season thicknesses to the post-season. The thickness of the triceps skinfold site decreased from the pre-season $(\mathrm{M}=14.85, \mathrm{SD}=6.59)$ to mid-season $(\mathrm{M}=13.22, \mathrm{SD}=6.9) \mathrm{t}(26)=3.698, \mathrm{p}=.001$ and again from the pre-season to postseason $(\mathrm{M}=12.59, \mathrm{SD}=7.35) \mathrm{t}(26)=5.35, \mathrm{p}<.001$. The midaxillary site was found to significantly decrease from the pre-season $(\mathrm{M}=16.52, \mathrm{SD}=7.21)$ to mid-season $(\mathrm{M}=14.67, \mathrm{SD}$ $=8.52) \mathrm{t}(26)=2.808, \mathrm{p}=.009$ and again from the pre-season to post-season $(\mathrm{M}=13.81, \mathrm{SD}=$ 7.35) $\mathrm{t}(26)=5.345, \mathrm{p}<.001$. The calf followed the same pattern as it decreased from pre-season $(\mathrm{M}=12.22, \mathrm{SD}=5.49)$ to mid-season $(\mathrm{M}=11.04, \mathrm{SD}=4.82) \mathrm{t}(26)=2.712, \mathrm{p}=.006$ and was found to be significantly lower by the post-season $(M=9.81, S D=4.74) t(26)=3.836, p<.001$. The thigh was found to significantly decrease from each testing period to the next being the highest during the pre-season $(\mathrm{M}=18.556, \mathrm{SD}=8.95)$, lower by the mid-season $(\mathrm{M}=17.19, \mathrm{SD}$ 
$=8.93)$, and further decreased by the post-season $(\mathrm{M}=15.7, \mathrm{SD}=8.24)$. Mid-season thickness was significantly lower than the pre-season thickness $\mathrm{t}(26)=3.257, \mathrm{p}=.003$, mid-season thickness was found to be significantly higher than the post-season thickness $t(26)=3.633, p=$ .001 , and the post-season thickness was significantly less than what was reported during the preseason $\mathrm{t}(26)=5.771, \mathrm{p}<.001$.

Significant changes in agility, speed, and aerobic power were also discovered throughout the course of the competitive season. From the pre-season to mid-season, the time it took for players' to complete the L-Drill was found to be significantly $(F(2,26)=6.687, p=.005$. Paired sample t-tests found that players became significantly more agile during the season when comparing their L-Drill times for the pre-season $(\mathrm{M}=8.36, \mathrm{SD}=.32)$ to the mid-season times $(\mathrm{M}=8.23, \mathrm{SD}=.36) \mathrm{t}(13)=3.128, \mathrm{p}=.008$. However, a significant decrease in player agility was detected during the second half of the season as players mid-season times were significantly lower than the times recorded during the post-season $(\mathrm{M}=8.55, \mathrm{SD}=.42) \mathrm{t}(13)=-3.101, \mathrm{p}=$ .008. Players 10 and $20 \mathrm{~m}$ sprint speed was also found to significantly change throughout the season $(\mathrm{F}(2,28)=10.104, \mathrm{p}<.001,(\mathrm{~F}(2,28)=6.768, \mathrm{p}=.001$ respectively. Paired sample t-tests revealed that these significant changes occurred during the first half of the season as the midseason results for the $10 \mathrm{~m}$ sprint were significantly higher by the mid-season $(\mathrm{M}=1.89, \mathrm{SD}=$ $.064) \mathrm{t}(14)=-3.429, \mathrm{p}=.004$. Speed continued to decrease as the post-season times were significantly slower in the post-season $(\mathrm{M}=1.91, \mathrm{SD}=.084)$ when compared to the pre-season $(\mathrm{M}=1.79, \mathrm{SD}=.099)$ as well $\mathrm{t}(14)=-4.406, \mathrm{p}=.001$. Twenty-meter speed followed the same general fluctuation as the ten-meter speed as the pre-season times $(\mathrm{M}=3.12, \mathrm{SD}=.15)$ were found to be significantly faster than the times reported during the mid-season $(\mathrm{M}=3.24, \mathrm{SD}=$ .11) $\mathrm{t}(14)=-3.123, \mathrm{p}=.007$. However, the post season times $(\mathrm{M}=3.21, \mathrm{SD}=.08)$ were slightly 
faster than the times reported during the mid-season, but still found to be significantly lower than the times reported prior to match-play $\mathrm{t}(14)=-2.915, \mathrm{p}=.011$.

The estimated aerobic power of participants was found to be significantly affected by participation in collegiate rugby union over the course of a season $(F(2,26)=9.667, p=.001$. Nevertheless, estimated aerobic power was found to significantly decrease from the mid-season to post-season $(\mathrm{M}=41.25, \mathrm{SD}=6.4) \mathrm{t}(13)=4.260, \mathrm{p}=.001$, and end up being lower by the post-season than when players were first assessed during the pre-season $\mathrm{t}(13)=3.956, \mathrm{p}=.002$.

Training and Match Loads were estimated by multiplying each player's reported rating of perceived exertion (RPE) by the number of minutes they either attended training or played during a match. The average combined load during the first half $(\mathrm{M}=15,505.55, \mathrm{SD}=4525.64)$ of the season was found to be lower than the load found during the second half of the season (M $=18,747.45, \mathrm{SD}=9222.77)$.

When looking specifically at intensity, the training sessions during the first half of the season $(M=12.69, S D=1.6)$ were found to be higher than the average RPE reported during the second half of the season $(\mathrm{M}=12.18, \mathrm{SD}=1.08)$. Similarly, the duration of training sessions during the first half of the season were also found to be higher $(M=110.22, S D=17.76)$ than the average duration of training sessions during the second half of the season $(\mathrm{M}=99.41, \mathrm{SD}=$ 13.09).

Unlike training intensities, match intensities during the first half of the season $(\mathrm{M}=$ 15.26, $\mathrm{SD}=1.26)$ were found to be lower than the intensities reported for the second half matches $(M=16.05, \mathrm{SD}=0.52)$. While the match intensity differences between the two portions of the season are rather minimal, the average intensities for the six playoff matches were higher $(\mathrm{M}=16.3, \mathrm{SD}=0.3)$ than the regular season matches during both the three first-half matches $(\mathrm{M}$ 
$=15.26, \mathrm{SD}=1.26)$ and two regular season second-half matches $(\mathrm{M}=15.32, \mathrm{SD}=0.07)$.

Players were also found to play deeper into matches during the second half of the season ( $M=$ $57.11, \mathrm{SD}=76)$ when compared to the first half $(\mathrm{M}=50.46, \mathrm{SD}=6.59)$. Playing time during the six playoff matches $(\mathrm{M}=58.92, \mathrm{SD}=2.02)$ was only slightly higher than the two second half matches and approximately 8-minutes longer than the three first half matches.

\section{Discussion}

While similar studies have been completed with international and adult amateur subjects, this is the first study to focus solely on changes in anthropometric and physiological characteristics of male collegiate rugby union players over the course of a competitive season.

The results of this study suggest collegiate rugby union athletes may experience significant changes in both anthropometric and physiological characteristics throughout a competitive season, likely affecting their performance on the pitch. From the beginning to end of a competitive season, players may find an increase in speed, agility, and a decrease in maximal aerobic power. Physically, players may notice an overall decrease in sum of skinfolds. It is interesting to note that despite the second half of the season being 3.5 weeks longer than the first half, 12 of the 15 significant changes found during either half of the season occurred during the first half. These results are not surprising as players were exposed to a greater amount of repeated high-intensity tempo-runs during the first month of the season in attempt to increase player fitness. As the season progressed, the team training sessions focused less on increasing fitness levels and more on maintaining the adaptations achieved and match strategy. The shift in training focus is likely the reason that 2 of the 3 significant changes that occurred during the second half were negative physiological adaptations. 
Over the 3-month season, the training duration and RPE decreased each month while average match-time and RPE for each player increased. Both of these results should be expected as the training objectives shifted from a conditioning and skill-based focus towards team runthroughs and conditioning maintenance. Training duration was effected as the season progressed and the sun set earlier in the evening. Similar to previous research, an overall decrease in training load was countered with an increase in match load as the season progressed (21). Average match duration for each player increased as the season carried on and starters were expected to player deeper into the match to try and allow the team to have a better chance of winning. Substitutions were made throughout each match, but only when the starters' performance started to tail-off and they became fatigued or became injured. An increase in match intensity would also make sense due to the increased duration and likelihood of player tougher opponents as the cohort progressed through the Division II Collegiate National Playoffs (21).

The anthropometric and physiological changes found from the pre-season to the midseason make sense with the corresponding high-intensity training players performed during the first half of the season. Like previous studies conducted with rugby union players and rugby league players, body mass was not found to significantly change over the course of a competitive season $(16,21,24,25,28)$. In the present study, fat-mass, lean-mass, and body fat percentage were estimated using ADP analysis and body density, sum of skinfolds, and estimated body fat percentage were estimated using the sum of 7-skinfolds and Siri equations from ACSM (30). Interestingly enough, both methods yielded different variations of body fat percentage during each half of the season. No significant changes for the estimated body fat percentage from the ADP analysis were found contradicting findings from previous research $(4,21,24,25,28,33)$. The estimated body fat percentage, via the sum of 7-skinfolds equation, body density via the Siri 
equation, and sum of 7-skinfolds were all found to decrease during the first and second-halves of the season also contradicting previous findings $(4,21,25,28,33)$. Unlike the results from the ADP analysis, the post-season estimated body fat percentage numbers were lower than what was reported during the pre-season. The differences of estimated body fat percentage between the ADP analysis and skinfolds do not come as a surprise as both are providing estimations based on different technology. According to ACSM's Health-Related Physical Fitness Assessment Manual, ADP has a standard error of estimate of \pm 2.2 to $\pm 3.7 \%$ while the 7 -site sum of skinfolds equation has a standard error of estimate of $3.5 \%$ (30). Due to scheduling and availability, 2 researchers were responsible for taking of all the skinfolds measures leaving the possibility of inter-testing variability as well. In regards to the skinfold sites individually, the present study found the thickness of each site to decrease from each collection period to the next except for the subscapular and abdominal sites. This pattern contradicts previous findings from a study monitoring amateur rugby league players over the course of their competitive season using the same skinfold sites as the current study. A majority of the site thicknesses previously reported were found to increase with each collection period (excluding the off-season) (21). A different study focusing on professional rugby union players over a 4-year period does agree with the decrease in sum of skinfolds during the first-half of the season (4). However, participants' sums of skinfolds were found to increase during the second-half of the season unlike the current study (4). Significant decreases were found for the pectoral, triceps, midaxillary, thigh, and calf sites over the course of the season likely due to the possibility of increased activity levels in those participating in rugby training and matches compared to the off-season. Depending on activity levels and eating habits of those assessed, greater changes in the appendages could be expected 
as the reduction of body fat would come from the secondary body fat storage sites before the primary sites.

When looking at whole-body lean and fat-mass, previous research does agree with the overall decrease in lean mass over a competitive season $(24,25,33)$. Only one study has reported a decrease in fat-mass during the second-half of the season contradicting the findings of the present study and other previous research $(21,25,28,33)$.

Changes in the physiological characteristics of the participants were much less clear compared to the body composition assessments. These less defined results may be due to the fact that as a club sport, training may be taken less seriously by some compared to others. No teamstructured conditioning sessions took place outside of the 2-3 weekly trainings each week, and even then, training attendance for some was much better than others. The possibility of a wide variety of conditioning habits outside of training for those who participated in the present study make it hard to say for sure whether any increases or decreases in performance of the assessments were due to the rugby season. It is also worth noting that as the season progressed, fewer players were able to participate in all of the physiological assessments due to lingering injuries that would prevent them from completing the assessment to their best ability. Therefore, the sampling size for each physiological test was $14-15$ subjects compared to the 27 subjects that participated in the body composition assessments.

No significant change was found for players' aerobic power capacity during the first half of the season. However, a significant in aerobic capacity was found during the second half with the average estimated aerobic power being lower than what was reported during the pre-season. By the end of the season, it was obvious that the overall performance of the multi-stage shuttlerun was not performed to volitional max-effort by some participants, which may explain the 
significant decrease in aerobic power during the second half of the season and season overall. These findings are similar to those of amateur rugby league and international rugby union players $(21,28)$. The aerobic capacity of amateur rugby league players was reported to increase during the first half and decrease during the second half, with the post-season scores to still remain higher than what was reported during the pre-season (21). Professional rugby union players were reported to experience an overall improvement of aerobic power over the course of an entire year with the largest increases occurring during the off-season (28). Similar to the amateur rugby league players, the increased aerobic power was found to be maintained during the first half of the season and slightly decrease during the second half remaining higher than what was reported during the off-season $(21,28)$.

Players also became significantly more agile during the first half of the season despite never participating in agility specific training. During the second half of the season, agility was found to significantly decrease and ended up worse than what was reported during the preseason. The findings of the present study contradict the lack of change in agility reported by the only other study known to assess agility in amateur rugby league players throughout a competitive season (21). It is also worth noting that the increase in L-drill performance reported in the present study may be due to players becoming more familiar with the drill the second time around.

Increases in speed during a competitive season for professional rugby league players, amateur rugby league players, and international rugby union players have been reported by in the past $(21,28,53)$. However, the present study found players' speed for both 10 and $20 \mathrm{~m}$ sprints to decrease significantly during the first half of the season and the entire season in general. While the increasing load of the season could be to blame for the decreases found in speed, no 
significant increases or decreases were reported for anaerobic power from each testing session to the next. Previous research also using a vertical jump test has reported increases in muscular power during the pre-season $(21,53)$. No significant increases or decreases were found for professional rugby union players at any point of the season in the past using a 20m anaerobic shuttle test (28). One other study focusing on professional rugby union players reported a 3.3 and 3.4\% decrease in upper and lower body power respectively throughout a 13-week professional rugby union season (2). Peak power from a jump squat and bench throw were used rather than a counter-movement jump. The variation of findings between the present study and past may indicate that further research should be conducted to determine which form of testing may lead to more accurate power quantification.

As for mobility, no significant changes were found at any point of the season for both FMS component tests agreeing with the lack of change in mobility throughout a season previously reported in professional rugby league players (53). Several limiting factors throughout the data collection process should be considered before drawing any final conclusions. First, being a club sport, participation for training and matches was not mandatory; which may have lead to inconsistent attendance during training sessions by participants. Another limitation was that the number of days between each data collection period was not standardized. Since players were asked to come in to either the exercise physiology lab or PE instructional gym at ISU on 3 separate occasions, it was difficult to schedule times for both locations that fit every subjects schedule and the researchers' schedule. Therefore, some subjects participated in testing later than the majority of the group. Also, some subjects could not attend every testing session due to scheduling conflicts. Another limitation is the lack of dietary control during the entire season. There were no dietary guidelines put forth by the team or the researchers, so players with 
different eating habits may have been affected differently by the conditioning protocols during training sessions. Rugby players also have a notorious reputation for binge-drinking following the completion of each match, which may affect their body composition and recovery from intense match play as well. It should also be kept in mind that majority of the studies carried out prior to this took place over longer competitive seasons and in some cases one or more full years. Because the American DII collegiate rugby season only takes place for 3 months, there was less time for anthropometric and physiological adaptations to occur.

\section{Conclusion}

From the results presented in this study, one could reasonably expect to observe different anthropometric and physiological changes over the course of a competitive season for male collegiate rugby union players. The results of player load monitoring indicate that the combined training and match loads from the $1^{\text {st }}$ half of the season were lower than the loads experienced during $2^{\text {nd }}$ half of the season. Despite the $2^{\text {nd }}$ half of the season being 3.5 weeks longer and including 5 more matches than the $1^{\text {st }}$ half of the season, a majority of the significant changes occurred from the pre-season to mid-season period. Therefore, the noticeable improvements in anthropometric and physiological performance during the 1st half of the season may be due to players beginning the season un-fit. It was also observed that the focus of the $1^{\text {st }}$ half training sessions was to increase players' conditioning through the incorporation of interval training at the beginning of most practices and improvement of various skills via drills. During the $2^{\text {nd }}$ half of the season, the team shifted focus towards team-walkthroughs and strategy as they planned for their next matches. Anthropometric changes throughout the season were found to include overall decreases in 5 of the 9 skinfold sites, a decrease in estimated body fat, body density, and sum of 
7-skinfolds by the end of the season. The lack of significant changes in body mass were likely due to the fluctuations in fat-mass and fat-free mass. It is possible that the increasing amount of fat-mass and decreased fat-free mass may have attributed to the significant decrease in physiological variables such as maximal aerobic power, speed, and agility as carrying excess fat mass requires more energy expenditure. As shown in this study and previous research (21), players' on-field performances may decline as the season progresses as recovery time between training and matches shrink, and players experience accumulating training loads. Depending on how far the team progresses into the post-season, match intensities may increase as well as the level of competition will likely increase. It is recommended that the player's participate in offseason conditioning and follow a tailored nutrition plan in order to optimize performance from one season to the next rather experiencing de-training and having to start from scratch at the beginning of each season. As a means of maintaining performance from the beginning to the end, the authors suggest implementing some sort of player monitoring during each training session and match to obtain an idea of how each individual is feeling. It is important to keep in mind that each team will train differently depending on their coaching staff and resources. This team in particular did not have a paid coaching staff. Teams with more or less resources may find different results compared to those find in the current study. 


\section{Practical Applications}

Previous research quantifying changes in anthropometric and physiological characteristics throughout a competitive season has been carried out with international rugby union players (28) and amateur rugby league players (21). However, no previous research has been conducted with American collegiate rugby union players throughout a competitive season. This study provides coaching and training staffs with important information regarding what type of anthropometric and physiological adaptations players may be exposed to as well as the level of fatigue and de-training they may experience as they progress through a season.

The changes in training and match loads throughout the season indicate that as a season carries on, players' performance on the pitch may decrease due to accumulating match loads and decreasing recovery times. Therefore, it is important for coaches and training staffs to utilize a load monitoring system, incorporation of various recovery modalities, and avoid over-working their athletes to make sure the athletes have a chance to recover after hard training and matches to increase recovery and feel prepared to perform at their best for their next competition. 
Table 1. Estimated body fat percentage, body density, and thickness of 9 skinfolds sites throughout the course of the season (Mean \pm Standard Deviation).

\begin{tabular}{cccc}
\hline Site & Pre-Season & Mid-Season & Post-Season \\
\hline Biceps $(\mathrm{mm})$ & $7.56 \pm 5.42$ & $7.37 \pm 4.68$ & $6.81 \pm 5.28$ \\
\hline Triceps $(\mathrm{mm})^{*}$ & $14.85 \pm 6.59$ & $13.22 \pm 6.9^{\mathrm{a}}$ & $12.59 \pm 6.4^{\mathrm{a}}$ \\
\hline Pectoral $(\mathrm{mm})^{*}$ & $14.96 \pm 7.4$ & $14.11 \pm 8.18$ & $13.33 \pm 7.35^{\mathrm{a}}$ \\
\hline${\text { Subscapular }(\mathrm{mm})^{*}}^{*}$ & $18.41 \pm 8.86$ & $17.1 \pm 8.84$ & $17.52 \pm 8.61$ \\
\hline Suprailliac $(\mathrm{mm})^{*}$ & $17.1 \pm 9.53$ & $16.37 \pm 8.96$ & $16.11 \pm 9.12$ \\
\hline Abdominal $(\mathrm{mm})^{*}$ & $27.2 \pm 9.6$ & $25.56 \pm 10.49$ & $26.22 \pm 10.33$ \\
\hline Thigh $(\mathrm{mm})^{*}$ & $18.56 \pm 8.95$ & $17.19 \pm 8.27^{\mathrm{a}}$ & $15.7 \pm 8.24^{\mathrm{a}, \mathrm{b}}$ \\
\hline Calf $(\mathrm{mm})$ & $12.22 \pm 5.49$ & $11.04 \pm 4.82^{\mathrm{a}}$ & $9.81 \pm 4.74^{\mathrm{a}}$ \\
\hline Midaxillary $(\mathrm{mm})^{*}$ & $16.52 \pm 7.21$ & $14.67 \pm 8.52^{\mathrm{a}}$ & $13.81 \pm 7.35^{\mathrm{a}}$ \\
\hline Sum of 7-Sites $(\mathrm{mm})$ & $127 \pm 52.43$ & $118.19 \pm 56.1^{\mathrm{a}}$ & $115.3 \pm 51.03^{\mathrm{a}}$ \\
\hline Estimated Bd & $1.061 \pm .014$ & $1.0641 \pm .015^{\mathrm{a}}$ & $1.0647 \pm .015^{\mathrm{a}}$ \\
\hline Estimated BF $(\%)$ & $16.6 \pm 6.21$ & $15.28 \pm 6.74^{\mathrm{a}}$ & $15.01 \pm 6.39^{\mathrm{a}}$ \\
\hline
\end{tabular}

* Included in sum of 7-sites. a: Significant difference from Pre-Season, b: Significant difference from Mid-Season. 
Table 2. Results of ADP Analysis and height throughout the course of the season (Mean \pm Standard Deviation).

\begin{tabular}{cccc}
\hline Measure & Pre-Season & Mid-Season & Post-Season \\
\hline Body Fat $(\%)$ & $18.1519 \pm 7.96$ & $17.6778 \pm 8.313$ & $18.337 \pm 8.1$ \\
\hline Fat-Free Mass $(\mathrm{kg})$ & $73.5941 \pm 9.11$ & $73.6722 \pm 9.12$ & $73.4233 \pm 8.89$ \\
\hline Fat-Mass $(\mathrm{kg})$ & $17.2426 \pm 10.32$ & $16.73 \pm 10.47$ & $17.5304 \pm 10.72$ \\
\hline Body Mass $(\mathrm{kg})$ & $90.8422 \pm 14.96$ & $90.4785 \pm 14.73$ & $90.9267 \pm 15.6$ \\
\hline Height $(\mathrm{cm})$ & $178.9504 \pm 7.26$ & $179.24 \pm 7.22$ & $179.35 \pm 7.21$ \\
\hline
\end{tabular}


Table 3. Fitness battery results throughout the course of the season (Mean \pm Standard Deviation).

\begin{tabular}{cccc}
\hline Test & Pre-Season & Mid-Season & Post-Season \\
\hline Vertical Jump Height $(\mathrm{cm})$ & $25.8572 \pm 5.23$ & $27.1429 \pm 3.45$ & $27.6429 \pm 3.4$ \\
\hline L-Drill Time $(\mathrm{s})$ & $8.3621 \pm .32$ & $8.2321 \pm .36^{\mathrm{a}}$ & $8.5493 \pm 0.42^{\mathrm{b}}$ \\
\hline 10m Sprint Time $(\mathrm{s})$ & $1.788 \pm 0.1$ & $1.892 \pm .063^{\mathrm{a}}$ & $1.91 \pm 0.08^{\mathrm{a}}$ \\
\hline 20m Sprint Time $(\mathrm{s})$ & $3.118 \pm 0.15$ & $3.238 \pm 0.11^{\mathrm{a}}$ & $3.2087 \pm 0.08^{\mathrm{a}}$ \\
\hline Right ASLR & $2.1765 \pm 0.73$ & $2 \pm 0.61$ & $2.2941 \pm 0.69$ \\
\hline Left ASLR & $2.1176 \pm 0.7$ & $2.0588 \pm .66$ & $2.2353 \pm 0.66$ \\
\hline Right SM & $2.2778 \pm 0.96$ & $2.22 \pm 0.81$ & $2.22 \pm 0.88$ \\
\hline Left SM & $1.94 \pm 0.87$ & $1.89 \pm 0.76$ & $1.94 \pm 0.8$ \\
\hline VO2max $(\mathrm{ml} / \mathrm{kg} / \mathrm{min})$. & $45.86 \pm 4.37$ & $47.6 \pm 8.01$ & $41.25 \pm 6.4^{\mathrm{a}, \mathrm{b}}$ \\
\hline
\end{tabular}

a: Significant difference from Pre-Season, b: Significant difference from Mid-Season. 
Table 4. Summary of the average training and match duration, rating of perceived exertion, and load throughout each month of the season (Mean \pm Standard Deviation).

\begin{tabular}{ccccccc}
\hline & \multicolumn{3}{c}{ Training } & \multicolumn{3}{c}{ Match } \\
\hline Month & Duration & RPE & Load & Duration & RPE & Load \\
\hline September & $113.80 \pm$ & $12.93 \pm$ & $1471.43 \pm$ & $50.88 \pm 9.27$ & $15.46 \pm$ & $786.75 \pm$ \\
& 18.54 & 1.57 & 329.53 & & 1.72 & 230.69 \\
\hline October & $105.40 \pm$ & $12.30 \pm$ & $1296.42 \pm$ & $55.16 \pm 3.71$ & $15.45 \pm$ & $852.42 \pm$ \\
& 15.32 & 1.27 & 263.18 & & 0.62 & 80.99 \\
\hline November & $93.75 \pm 6.94$ & $12.03 \pm$ & $1127.81 \pm$ & $56.63 \pm 3.38$ & $16.30 \pm$ & $922.88 \pm$ \\
& & 0.67 & 139.92 & & 0.33 & 28.35 \\
\hline
\end{tabular}


Table 5. The average training and match loads estimated during both halves of the season (Mean \pm Standard Deviation).

\begin{tabular}{ccccc}
\hline & $\begin{array}{c}1^{\text {st }} \text { half Training } \\
\text { Load }\end{array}$ & $\begin{array}{c}1^{\text {st }} \text { half } \\
\text { Match Load }\end{array}$ & $\begin{array}{c}2^{\text {nd }} \text { half Training } \\
\text { Load }\end{array}$ & $\begin{array}{c}2^{\text {nd }} \text { half } \\
\text { Match } \\
\text { Load }\end{array}$ \\
\hline Average Load & $13328.87 \pm 4220.37$ & $2176.68 \pm$ & $13775.81 \pm 6530.93$ & $4971.64 \pm$ \\
& & 1063.46 & 3264.20 \\
\hline Average & & $15505.55 \pm$ & & $18747.45 \pm$ \\
Combined Load & & 4525.64 & & 9222.77 \\
\hline
\end{tabular}

Load $=$ Reported RPE $\mathrm{x}$ minutes of match or training session participated in. 
Table 6. Break down of the average playing time, intensity, and load from the first half and second half matches. The second half matches are also broken down even further into the regular season and playoff matches (Mean \pm Standard Deviation).

\begin{tabular}{ccccc}
\hline & $\begin{array}{c}1^{\text {st }} \text { Half Matches } \\
(\mathrm{N}=3)\end{array}$ & $\begin{array}{c}\text { 2nd-Half } \\
\text { Season } \\
\text { Matches } \\
(\mathrm{N}=8)\end{array}$ & $\begin{array}{c}\text { 2nd-Half } \\
\text { Regular } \\
\text { Season } \\
\text { Matches } \\
(\mathrm{N}=2)\end{array}$ & $\begin{array}{c}\text { Playoff } \\
\text { Matches } \\
(\mathrm{N}=6)\end{array}$ \\
\hline $\begin{array}{c}\text { Average Playing } \\
\text { Time }\end{array}$ & $50.46 \pm 6.59$ & $58.47 \pm 1.92$ & $57.11 \pm 0.76$ & $58.92 \pm 2.02$ \\
\hline Average Intensity & $15.26 \pm 1.26$ & $16.05 \pm 0.52$ & $15.32 \pm 0.07$ & $16.3 \pm 0.3$ \\
\hline Average Load & $770.26 \pm 166.4$ & $938.56 \pm$ & $874.7 \pm 7.32$ & $960.07 \pm$ \\
& & 47.13 & & 30.21 \\
\hline
\end{tabular}


Table 7. Average training and playing time, rating of perceived exertion, and estimated load for training and matches (Mean \pm Standard Deviation).

\begin{tabular}{cccc}
\hline Period & Duration (Min.) & RPE & Estimated Load \\
\hline First Half Training & $110.22 \pm 17.76$ & $12.69 \pm 1.6$ & $1398.79 \pm 316.27$ \\
\hline Second Half Training & $99.41 \pm 13.09$ & $12.18 \pm 1.08$ & $1210.55 \pm 239.85$ \\
\hline First Half Matches & $50.46 \pm 6.59$ & $15.26 \pm 1.26$ & $770.26 \pm 166.4$ \\
\hline Second Half Matches & $58.47 \pm 1.92$ & $16.05 \pm 0.52$ & $938.56 \pm 47.13$ \\
\hline
\end{tabular}




\section{FIGURES}

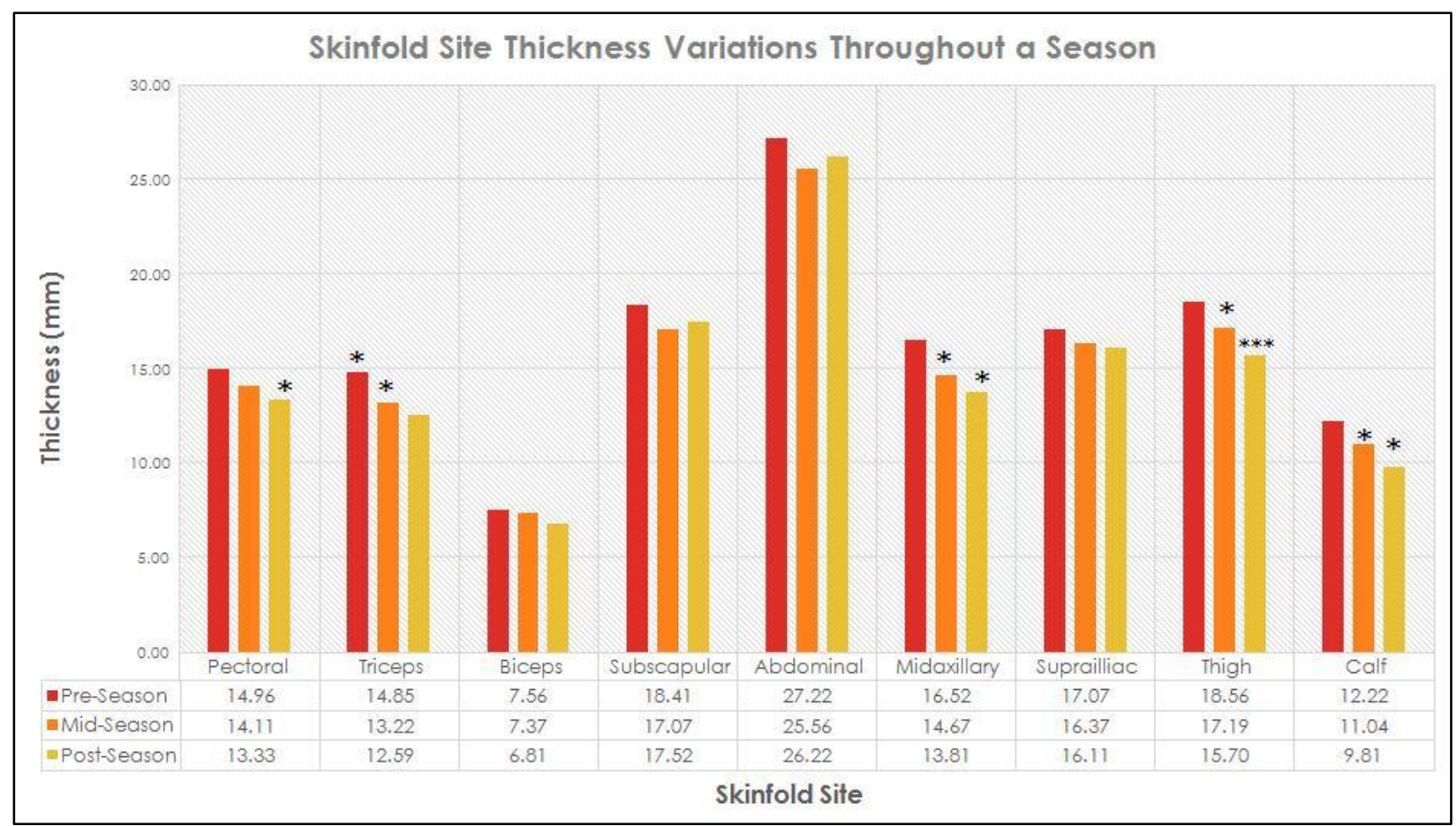

Figure 1. Visual Representation of Thickness Changes in Skinfold Sites Throughout the Season.

*: Significant difference from Pre-Season, **: Significant difference from Mid-Season. 


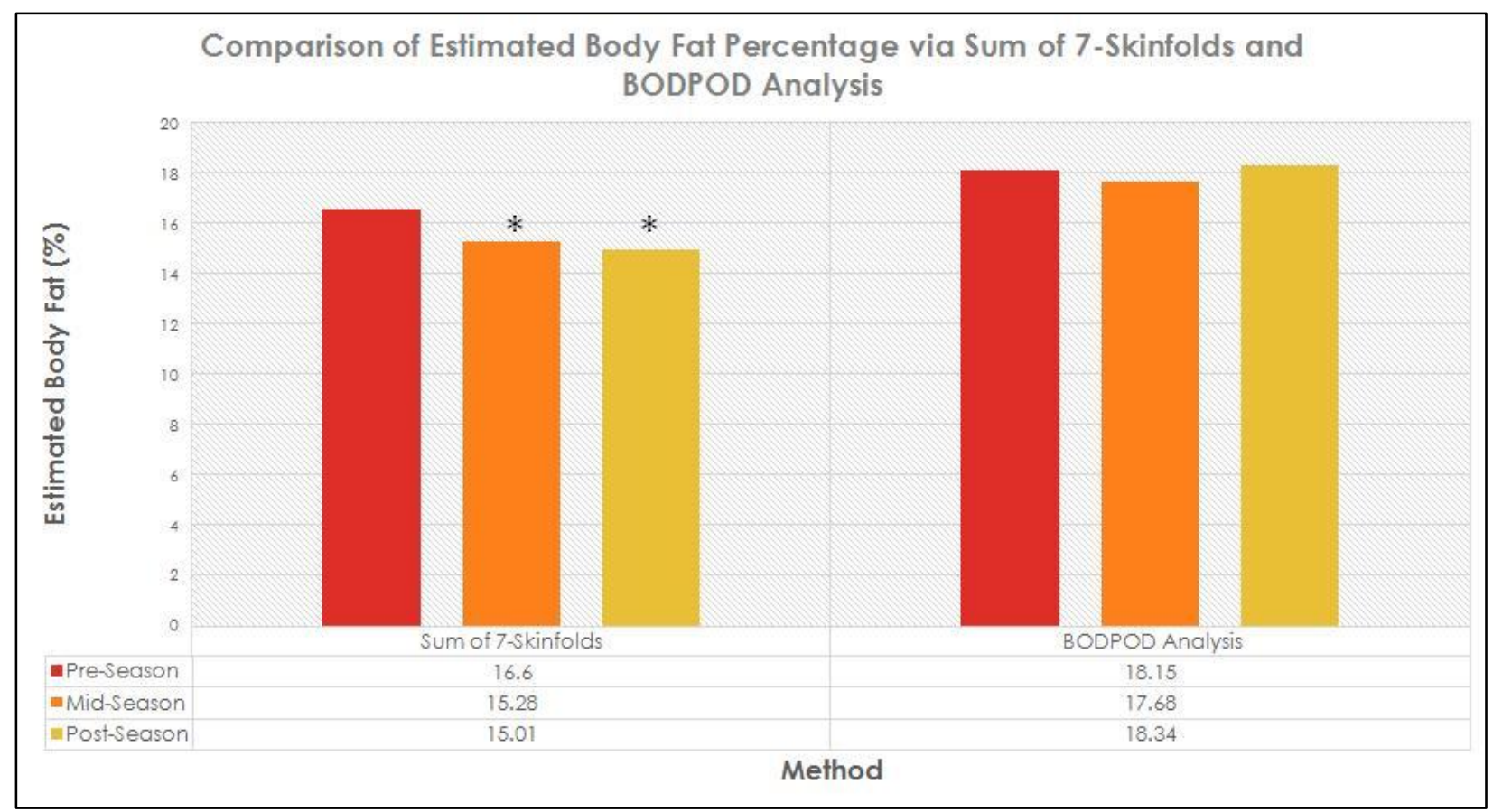

Figure 2. Visual representation of estimated body fat percentages found via sum of 7-skinfolds and ADP Analysis. *: Significant difference from Pre-Season. 


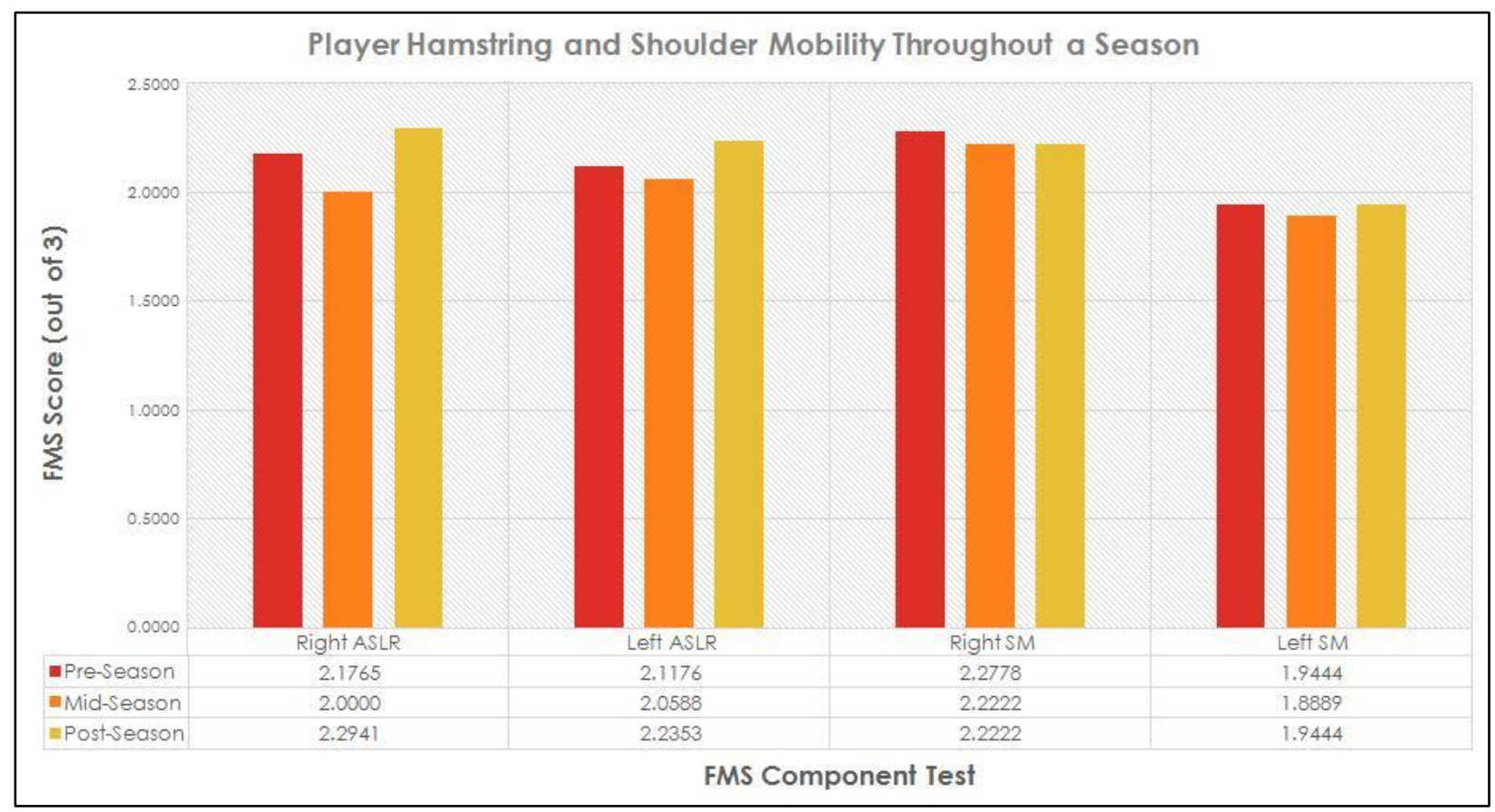

Figure 3. Visual representation of changes in right and left active straight-leg raise and shoulder mobility FMS component tests. 


\section{References}

1. Appleby, B, Newton, R, and Cormie, P. "Changes in Strength over a 2-Year Period in Professional Rugby Union Players.” Journal of Strength and Conditioning Research 26.9 (2012): 2538-2546. Print.

2. Argus, C, Gill, N, Keogh, J, Hopkins, W, and Beaven, M. "Changes in Strength, Power, and Steroid Hormones During a Professional Rugby Union Competition.” Journal of Strength and Conditioning Research 23.5 (2009): 1583-1592. Print.

3. Austin, D, Gabbett, T, and Jenkins, D. "The Physical Demands of Super 14 Rugby Union." Journal of Science and Medicine in Sport 14 (2011): 259-263. Print.

4. Austin, D, Gabbett, T, and Jenkins, D. "Repeated High-Intensity Exercise in Professional Rugby Union.” Journal of Sports Science 29 (2011): 1105-1112.

5. Bell, William. "Body Composition of Rugby Union Football Players." British Journal of Sports Medicine 13 (1979): 19-23. Print.

6. Cahill, N, Lamb, K, Worsfold, P, Heady, R, and Murray, S. "The Movement Characteristics of English Premiership Rugby Union Players.” Journal of Sports Science 31 (2013): 229237.

7. Comfort, C, Graham-Smith, P, Matthews, M, and Bamber, C. "Strength and Power Characteristics in English Elite Rugby League Players." Journal of Strength and Conditioning Research 25.5 (2011): 1374-1384. Print.

8. Coughlan, G, Green, B, Pook, P, Toolan, E, O’Connor, S. "Physical Game Demands in Elite Rugby Union: A Global Positioning System Analysis and Possible Implications for Rehabilitation." Journal of Orthopaedic and Sports Physical Therapy 41.8 (2011). Online.

9. Crewther, B, McGuigan, M, Gill, N. "The Ratio and Allometric Scaling of Speed, Power, and Strength in Elite Male Rugby Union Players.” Journal of Strength and Conditioning Research 25.7 (2011): 1968-1975. Print.

10. Cunniffe, B, Proctor, W, Baker, J, and Davies, B. "An Evaluation of the Physiological Demands of Elite Rugby Union Using Global Positioning System Tracking Software." Journal of Strength and Conditioning Research 12.4 (2009): 1195-1203. Print.

11. Cunningham, D, Shearer, D, Drawer, S, Eager, R, Taylor N, Cook, C, Kilduff, L. "Movement Demands of Elite U20 International Rugby Union Players." PLoS ONE 11.4 (2016).Online.

12. Deutsch, M, Kearny, G, and Rehrer, N. "Time-Motion Analysis of Professional Rugby Union Players During Match-Play.” Journal of Sports Science 25 (2007): 461-472. Print. 
13. Delahunt, Eamonn, Byrne, Risteard, Doolin, Rachel, McInerney, Rory, Ruddock, Ciaran, and Green, Brian. "Anthropometric Profile and Body Composition of Irish Adolescent Rugby Union Players Aged 16-18." Journal of Strength and Conditioning Research 27.12 (2013): 3252-3258. Print.

14. Dubois, R, Paillard, T, Lyons, M, McGrath, D, Maurelli, O, and Prioux, J. "Running and Metabolic Demands of Elite Rugby Union Assessed Using Traditional, Metabolic Power, and Heart Rate Monitoring Methods." Journal of Sports Science and Medicine 16 (2017): 84-92. Print.

15. Durandt, J, du Toit, S, Borresen, J, Hew-Butler, T, Masimia, H, Jakoet, I, and Lambert, M. "Fitness and Body Composition Profiling of Elite Junior South African Rugby Players.” South African Journal of Sports Medicine 18.2 (2006): 38-45.Print.

16. Duthie, G, Hopkins, W, Livingstone, S, and Hooper, S. "Anthropometry Profiles of Elite Rugby Players: Quantifying Changes in Lean Mass.” British Journal of Sports Medicine 40 (2006): 202-207. Print.

17. Duthie, G, Pyne, D, and Hooper, S. “Applied Physiology and Game Analysis of Rugby Union.” Journal of Sports Medicine 33.13 (2003): 973-991. Print.

18. Duthie, G, Pyne, D, and Hooper, S. "Time Motion Analysis of 2001 and 2002 Super 12 Rugby." Journal of Sports Science 23 (2005): 523-530. Print.

19. Duthie, G, Pyne, D, Marsh, D, and Hooper, S. "Sprint Patterns in Rugby Union Players During Competition”. Journal of Strength and Conditioning Research 20 (2006): 208 214. Print.

20. Fuller, Colin, Taylor, Aileen, Brooks, John, and Kemp, Simon. "Changes in the Stature, Body Mass, and Age of English Professional Rugby Players: A 10-Year Review.” Journal of Sports Sciences 31.7 (2013): 795-802. Print.

21. Gabbett, T. "Changes in Physiological and Anthropometric Characteristics of Rugby League Players During a Competitive Season." Journal of Strength and Conditioning Research 19.2 (2005): 400-408. Print.

22. Gabbett, T. "Quantifying the Physical Demands of Collision Sports: Does Microsensor Technology Measure What it Claims to Measure?" Journal of Strength and Conditioning Research 27.8 (2013): 2319-2322. Print.

23. Gannon, E, Stokes, K, and Trewartha, G. "Strength and Power Development in Professional Rugby Union Players over a Training and Playing Season.” International Journal of Sports Physiology and Performance (2015). Online. 
24. Georgeson, E, Weeks, B, McLellan, C, and Beck, B. "Seasonal Change in Bone, Muscle, and Fat in Professional Rugby League Players and it's Relationship to Injury: A Cohort Study." BMJ Open 2 (2012) Online.

25. Harley, J, Hind, K, O’Hara, J. “Three-Component Body Composition Changes in Elite Rugby League Players During a Super League Season, Measured by Dual-Energy X-Ray Absorptiometry." Journal of Strength and Conditioning Research 25.4 (2011): 1024-1029. Print.

26. Hartwig, T, Naughton, G, Searl, J. "Motion Analyses of Adolescent Rugby Union Players: A Comparison of Training and Game Demands." Journal of Strength and Conditioning Research 25.4 (2011): 966-972. Print.

27. Higham, D, Pyne, D, Anson, J, Dziedzic, C, and Slater G. "Distribution of Fat, Non- Osseous Lean and Bone Mineral Mass in International Rugby Union and Rugby Sevens Players.” International Journal of Sports Medicine (2013). Online.

28. Holymard, D, Hazeldine, R. "Seasonal Variation in the Anthropometric and Physiological Characteristics of International Rugby Union Players. " Science and Football II: Proceedings of the Second World Congress of Science and Football (1993): 21-26. Print.

29. Jones, M, West, D, Harrington, B, Cook, C, Bracken, R, Shearer, D, and Kiduff, L. "Match Play Performance Characteristics that Predict Post-Match Creatine Kinase Responses in Professional Rugby Union Players." BMC Sports Science, Medicine, and Rehabilitation 38.6 (2014). Online.

30. Kaminsky, L. (2014). ACSM's Health-Related Physical Fitness Assessment Manual (4 ${ }^{\text {th }}$ ed.) Philadelphia, PA: Lippincott Williams \& Wilkins.

31. Lacome, M, Piscione, J, Hager, J, and Bourdin, M. “A New Approach to Quantifying Physical Demand in Rugby Union.” Journal of Sports Science 32 (2014): 290-300. Print.

32. LaMonica, M, Kukuda, D, Miramonti, A, Beyer, K, Hoffman, M, Boone, C, Tanigawa, S, Wang, R, Church, D, Stout, J, and Hoffman, J. "Physical Differences Between Forwards and Backs in American Collegiate Rugby Players." Journal of Strength and Conditioning Research 30.9 (2016): 2382-2391. Print.

33. Lees, M, Oldroyd, B, Jones, B, Brightmore, A, O'Hara, J, Barlow, M, Till, K, and Hind, K. "Three-Compartment Body Composition Changes in Professional Rugby Union Players Over One Competitive Season: A Team and Individualized Approach." Journal of Clinical Densiometry: Assessment \& Management of Musculoskeletal Health 20 (2017): 50-57. Print. 
34. Mayorga-Vega, D, Aguilar-Soto, P, and Viciana, J. "Criterion-Related Validity of the 20-MS Shuttle Run Test for Estimating Cardiorespiratory Fitness: A Meta-Analysis.” Journal of Sports Science and Medicine 14 (2015): 536-547. Print.

35. McLaren, S, Weston, M, Smith, A, Cramb, R, and Portas, M. "Variabilitiy of Physical Performance and Player Match Loads in Professional Rugby Union." Journal of Science and Medicine in Sport (2015). Online.

36. McLean, D. "Analysis of the Physical Demands of International Rugby Union." Journal of Sports Science 10 (1992): 285-296. Print.

37. Nakamura, F, Pereira, L, Moraes, J, Kobal, R, Kitamura, K, Cal Abad, C, Teixeira Vaz, L, And Loturco, I. "Physical and Physiological Differences of Backs and Forwards from the Brazilian National Rugby Union Team.” Journal of Sports Medicine and Fitness (2016). Online.

38. Nicholas, Ceri. "Anthropometric and Physiological Characteristics of Rugby Union Football Players.” Journal of Sports Medicine 6 (1997): 375-396. Print.

39. Olds, T. "The Evolution of Physique in Male Rugby Union Players in the Twentieth Century" Journal of Sports Sciences 19 (2001): 253-262. Print.

40. Owen, S, Venter, R, du Toit, S, and Kraak, W. "Acceleratory Match-Play Demands of a Super Rugby Team over a Competitive Season.” Journal of Sports Sciences (2015). Online.

41. Quarrie, K, Handcock, P, Waller, A, Chalmers, D, Toomey, M, and Wilson, B. "The New Zealand Rugby Injury and Performance Project. III. Anthropometric and Physical Performance Characteristics of Players." British Journal of Sports Medicine 29.4 (1995): 263-270. Print.

42. Quarrie, K, Handcock P, Toomey, M, and Walter, A. "The New Zealand Rugby Injury and Performance Project. IV. Anthropometric and Physical Performance Comparisons between Positional Categories of Senior A Rugby Players." British Journal of Sports Medicine 30 (1996): 53-56. Print.

43. Quarrie, K, Hopkins, W, Anthony, M, and Gill, N. "Positional Demands of International Rugby Union: Evaluation of Player Actions and Movements." Journal of Science and Medicine in Sport 16 (2013): 353-359. Print.

44. Roberts, S, Trewartha, G, Higgitt, R, El-Abd, J, and Stokes, K. "The Physical Demands of Elite English Rugby Union.” Journal of Sports Science 26 (2008): 825-833. Print.

45. Reardon, C, Tobin, D, Delahunt, E. “Application of Individualized Speed Thresholds to Interpret Position Specific Running Demands of Elite Professional Rugby Union: A GPS Study." PLoS ONE 10.7 (2015). Online. 
46. Sedeaud, Adrien, Schipman, Julien, Tafflet, Muriel, Hager, Jean-Philippe, and Toussaint, Jean-Francois. "How they won Rugby World Cup through Height, Mass, and Collective Experience." British Journal of Sports Medicine (2012): 1-5. Online.

47. Smart, D, Hopkins, W, Gill, N. "Differences and Changes in the Physical Characteristics of Professional and Amateur Rugby Union Players. ” Journal of Strength and Conditioning Research 27.11 (2013): 3033-3044. Print.

48. Suarez-Arrones, L, Portillo, L, Gonzalez-Rave, J, Munoz, V, and Sanchez, F. "Match Running Performance in Spanish Elite Male Rugby Union using Global Positioning Software." Isokinetic Exercise Science 20 (2012): 77-83.

49. Tee, J, Klingbiel, J, Collins, R, Lambert, M, and Coopoo, Yoga. "Preseason Functional Movement Screen Component Tests Predict Severe Contact Injuries in Professional Rugby Union Players.” Journal of Strength and Conditioning Research 30.11 (2016): 3194-3203. Print.

50. Tee, J, Lambert, M, and Coopoo, Y. "Impact of Fatigue on Positional Movements During Professional Rugby Union Match Play" International Journal of Sports Physiology and Performance (2016). Online.

51. Van Gent, Maya and Spamer, Emanuel. "Comparisons of Positional Groups in Terms of Anthropometric, Rugby-Specific Skills, Physical and Motor Components among U 13, U 16, U 18, and U 19 Elite Rugby Players." Journal of Kinesiology 37 (2005):50-63. Print.

52. Venter, R, Opperman, E, and Opperman S. "The Use of Global Positioning System (GPS) Tracking Devices to Assess Movement Demands and Impacts in Under-19 Rugby Union Match-Play." Afr Journal of Physical Health Education, Recreation, and Dance 17 (2011): 1-8.

53. Waldron, M, Gray, A, Worsfold, P, and Twist, C. "The Reliability of Functional Movement Screening and In-Season Changes in Physical Function and Performance Among Elite Rugby League Players.” Journal of Strength and Conditioning Research 30.4 (2014): 910-918. Print.

54. Zemski, Adam, Slater, Gary, Broad, Elizabeth. "Body Composition Characteristics of Elite Australian Rugby Union Athletes According to Playing Position and Ethnicity.” Journal of Sports Sciences (2015): 1-8. Print.

55. Ziv, G and Lidor, R. "On-Field Performances of Rugby Union Players-A Review." Journal of Strength and Conditioning Research 30.3 (2015): 881-892. Print. 


\section{CHAPTER II:}

\section{EXTENDED REVIEW OF LITERATURE}

\section{General Overview}

Rugby union is a physically demanding sport broken up into two-forty-minute halves. Each team consists of 23 players per roster with 15 players representing each side on the pitch at one time. Of the 15 players from each team, players can be broken-up into 2 broad categories of positions; forwards and backs. Previous research has broken up these broad categories even further depending on their respective sample populations. Studies with larger sample sizes were able to break up the broad groups of forwards and backs into smaller sub-categories based on positional requirements. Within the forwards have been broken up into the "front row" consisting of a hookers and 2 props, the "second row" otherwise known as the locks, and the "back row" represented by 2 flankers and the number 8 -man. All in all, there are 8 forwards on the pitch

from each squad. Of the 7 backs, generally, 3 sub-groups are used: "inside backs", "centers", and the "back 3" or "outside backs". The inside backs include the scrumhalf and flyhalf; the centers consist of the inside and outside center, while the back 3 consist of 2 wings and a fullback.

Similar to other team sports, each position on the pitch has a specific role as each member of the team must work together in order to outscore the opponent. Different positions have been found to have different anthropometric traits dictated by the positional role and physiological demands for that position. During a match, there are 2 main periods of play; a setpiece and open-play. Set pieces are used to restart play after a turnover and include events such as lineouts, scrums, and kickoffs. Open-play refers to the continuous periods of play between setpieces. All players on the pitch regardless of position are expected to be involved rucking, tackling, running, kicking, and mauling. Scrums, rucks, line-outs, and mauls each involve more 
static exertion as each team fights for possession of the ball. In a scrum, all 8 forwards bind-up together and on the referee's signal, try to drive the opposition back to either maintain or steal possession of the ball. The offensive team has the "put-in," where the scrumhalf will put the ball between both teams as the hooker tries to hook the ball backwards towards their respective forward pack. Line-outs involve lifting a teammate to try and get up as high as possible while the ball is thrown into play after the ball has been put "into touch," or taken out of bounds. A maul occurs when one team either intentionally or unintentionally holds the ball or is driven forward by their teammates until the maul either collapses or is held-up. A ruck occurs when an offensive and defensive player have engaged in battling for possession of the ball following a tackle in open-play. All players on the pitch have the opportunity to carry, pass, place, or kick the ball during open-play. Typically, the forwards will carry the ball to set-up the next phase of play. In rugby union there is an unlimited number of phases for each offensive team as long as the offensive team maintains possession without committing an infraction or putting the ball into touch. Generally, the backs will be involved with more open-space running as they attack the opposition's space via running or kicking to try to gain better field positioning and work towards the opposition's try-zone.

Rugby Union is a specific code of Rugby with many different levels and leagues based on skill-level and age. The sport itself has been around for over 200 years and is played in many countries around the globe. Rugby Union has been evolving since its creation and became a professional sport in 1995. The first Rugby World Cup took place in 1987 with 16 international teams participating without any required qualification. The 2015 Rugby World Cup took place in England and required 20 different nations to qualify in order to participate. Since 1987, there have been 8 total world cups occurring every 4 years. Rugby Union differs from Rugby League 
based on each respective sport's rules or laws. Rugby Union involves rucks, counter rucks, contested scrums, lineouts, tackling, kicking, an unlimited number of possession phases, and 15 players per side. Rugby League does include most of these same aspects; however, it does not include counter-rucking, contested scrums, lineouts, unlimited phase-play, and only has 13 players per side. Flankers are not included in Rugby League where there are definitely involved in Rugby Union, accounting for the $14^{\text {th }}$ and $15^{\text {th }}$ players that are not in Rugby League. The scoring is also different between each competition. In Rugby Union, 5 points are awarded for a Try while 3 points are awarded for a drop-goal and penalty kick, and 2 points are awarded for a successful conversion kick. A Try occurs when a player places the ball on the ground in the oppositions Try-Zone with possession and downward pressure. Tries are followed by a conversion kick. The conversion kick must be executed from the angle of where the ball was placed down in the Try-Zone. Therefore, if a player scored in the left corner of the Try-Zone, the kicker must then set up the ball in a direct line from where the ball was placed and find the desirable angle going as far back as needed to kick the ball through the uprights. A drop-goal occurs when a player bounces the ball off the ground and kicks it through the uprights of the opposing team. A penalty kick can take place if a team decides to kick the ball through the uprights instead of utilizing other penalty options. This can occur at any moment of the match. Penalty kicks are placed on the ground and are similar to field goals in American Football. In Rugby League, a Try is worth 4 points while the conversion after and penalty kicks are worth 2 points. Drop-goals in Rugby League are only worth 1 point. Despite the increasing interest in rugby union within the United States, little research has focused on American collegiate rugby union athletes. All but one article reviewed include participants from both the Northern and Southern Hemisphere, professional, amateur, and international rugby union and rugby league 
players. Physiological performance and anthropometric characteristics have been found to change from level of play with match intensities being the highest for international rugby union $^{32,46}$. Similar anthropometric and physiological characteristics previously found in adult players have also been identified in adolescents and more recently, at the American collegiate level.

\section{Rugby Research}

While numerous studies have focused on adolescent, collegiate, amateur, professional, and international rugby union and league players, few have focused on American collegiate rugby union players. In fact, only one study published in 2016 was found focusing on American male collegiate rugby union players from the University of Central Florida. Players were asked to perform a battery of fitness tests in order to determine both physiological and anthropometric differences of forwards and backs. The study published by LaMonica in 2016 confirmed similar differences in anthropometric and physiological characteristics of which have been found in previous studies. It is important to take in consideration the differences between American collegiate rugby and other age-groups and levels of play due to the fact that rugby union is still a growing sport in America. Many players do not begin to play until their freshman year of college or during their later years of high-school as few youth leagues exist compared to soccer, baseball, basketball, football or any other major sport. Many former high-school football players look to American club rugby during college to fill the void of no longer competing in a physical sport such as American football. Therefore, the level of skill is usually lower in American collegiate players compared to those of other countries where rugby is much more popular and available to play at a younger age. USA Rugby has been working to promote youth-rugby and aims at making the sport to be just as popular as any other traditional American sport. There is 
great potential for a future generation of American kids to grow up from a young age playing rugby and learning the required skills and tactics needed to compete with the rest of the world.

Past studies have utilized time-motion-analysis of matches to try and categorize the movement demands of the different positions in rugby union and identify the demands of rugby union based on the actions of players during match-play (55). While, time-motion analysis is truly an observation-based strategy to identify the physiological demands of the sport, the development of wearable microtechnology has led the use of Global Positioning System (GPS) devices to be used during match-play (55). With the increasingly growing market of wearable micro-technology devices, there has been an issue of whether or not these devices provide accurate results. While there are a multitude of studies using wearable GPS units to try and determine the physiological demands of rugby union, recently it has been suggested that most previous research utilized GPS devices sampling at $5 \mathrm{~Hz}$ or less and are 6-times more prone to error compared to newer devices sampling at $10 \mathrm{~Hz}$ (45). Another issue with previous research using GPS units with the methodology used by previous GPS studies when trying to quantify the amount of high-speed-running players completed during match-play via default absolute speed zones provided by the GPS manufacturers (45). Therefore, it has been suggested that the findings from previous studies using GPS devices with less than $5 \mathrm{~Hz}$ or absolute speed zones may overestimate the amount of high-speed-running performed by the wings, fullback, and fly-half while the amount of high-speed-running performed by the front and second row may be underestimated due to their lower maximal speeds (45). Individualized speed zones should be employed by future research to attain more accurate demands of the sport (45).

It has been suggested that only the minimax X wearable device (Catapult Sports, Melbourne, Australia) was a valid tool for measuring collisions (22). To date, the minimaxX 
wearable device has yet to be validated for the use of quantifying collisions during rugby union (45). A different study published in 2012 was reportedly able to automatically detect collisions through the use of accelerometer data provided by a GPSports units (GPSports, Canberra, Australia) and tackle-detection algorithms (22). Several studies agree that the use of accelerometers via wearable GPS devices reported that backs were exposed to a greater number of both total and high-intensity G-forces compared to forwards (50). With the previously determined notion that forwards are exposed to more impacts and collisions during match-play than backs due to positional role variances, Tee et al. suggested that the increased G-force exposure in backs was likely due to the higher volume of decelerations and accelerations (50). With the discrepancy on the effectiveness of GPS microsensing technology in sensing collisions, majority of research using GPS technology has focused on determining velocities, accelerations, decelerations, and distances covered $(22,45,50)$.

One physiological aspect of rugby union that can be missed by microsensing technology is the static exertions that forwards are put through during scrums, rucks, lineouts, and mauls $(14,22,37,39,45,50,55)$. It is important for sport scientists to keep both collisions and static exertions in mind when trying to quantify physiological demands of rugby union. It has been suggested that researchers should utilize both video analysis and GPS microsensors to get the most accurate analysis $(22,45)$.

Since rugby's creation over 200 years ago, there has been an obvious difference between players' body composition and anthropometric profile. These varieties in body size allow players to perform their position-specific roles to the best of their abilities $(5,17,27,38,42,54)$. The fact that Rugby Union requires players of all different shapes and sizes to work together completing 
their position-specific roles to win the match makes it similar to most other team sports $(5,17,27$, $38,42,54)$.

Of the forwards, the props make up $2 / 3$ of the front row with a hooker in between them. Props need to be powerful athletes as their main role is to win control of the ball through scrums and line-outs. While they do not typically carry the ball very often, they are involved with tackling and rucking frequently. Hookers are generally the shortest and lightest of the forwards with the main role of winning possession of the ball in scrums $(8,17,42)$. In scrums, hookers communicate with scrumhalves as the ball is placed into the scrum by the scrumhalf. Hookers then hook the ball backwards towards their team using their foot. Hookers also usually throw in the ball for lineouts as each team jumps up in the air battling for possession of the ball. The locks or second row, are usually the tallest players of the entire team. Besides height, locks need to have good jumping abilities for winning lineouts. Locks are usually lifted up to catch the ball when the ball is thrown in by the hookers. They also provide power in the scrums and rucks in phase play $(17,27)$. Generally, the front and second row players are thought of as the more "traditional" forwards as they are usually the heavier, slower, but stronger players on the pitch $(6,11,14,40)$. The back row consists of flankers and the Number 8 man. Both of these positions require power, mobility, speed, acceleration, and endurance in phase play $(17,38,42)$. Flankers are generally considered the best overall athletes of the entire team. Both positions are required to assist in scrum drives, tackling, and rucking $(6,8,40)$. High levels of fitness are required for flankers and the 8-man position as they will be running all over the pitch to participate in contact situations fighting for possession of the ball and running with the ball in hand as well $(6,8,40)$.

There are 5 different positions in the back-line. Scrumhalves and fly halves are generally grouped together as half-backs. Scrumhalves play a very important role as they control 
possession of the ball $(17,38)$. Decision-making is a major part of being a successful scrumhalf. Deciding where to distribute the ball requires high-levels of endurance to get to each ruck or breakdown and redistribute the ball. Scrumhalves are generally the lightest and shortest of all players on a team $(5,15)$. Fly halves are the playmakers of the team as they run offensive attacks utilizing the speed of the back-line to find holes to run through or space to kick and chase to. Centers are the most physical of the backs and play a big role in defense and offense by tackling and running through opponents or sometimes running decoy lines to trick the opposition. The outside backs consist of two wings and a full-back. The main role of the outside backs is to cover kicks, chase down kicks, and use their speed to get past their opponents and score (5).

Overall, it is agreed that the total distance covered by rugby union players is be smaller compared to other sports such as soccer (55). A wide-range of total distance covered per match has been reported to be between $4500-7500 \mathrm{~m}(14,55)$. The large variation of distance is likely due to factors such as position, weather, team strategy, and level of play $(14,45,55)$. Unlike soccer, rugby union players experience additional physically exhausting moments such static exertion events like scrums, lineouts, rucks, and mauls that involve players wrestling for possession of the ball $(14,22,36,44,49,50,55)$. Rugby union is a highly intermittent sport with short period's high-intensity activity followed by longer periods of low-intensity movements such as walking or jogging. In general, forwards have been reported to have shorter resting periods as they are engaged in contact more often and have been reported to have longer periods of time performing higher intensity activity $(14,45,55)$. Backs on the other have been reported to spend more time on the pitch walking and sprinting and less time engaged in contact $(14,45,55)$. It seems that the glycolytic pathway is the primary energy provider for players as a variety of requirements such as tackling, rucking, mauling, sprinting, cutting, and evading defenders occur 
throughout a rugby union match $(3,4,6,11,12,14,31,37,45,47,50,55)$. To some surprise, it has been reported that player performance has been found to either be maintained or decrease across a match $(29,31,42,50)$. A decrease in physiological capacities should be expected in a highintensity sport such as rugby union but 2 studies have reported players being able to maintain high-intensity running distance and that there was no obvious difference between the two halves. On the contrary, 2 studies have found in player performance throughout a rugby union match. The first study reported significant decreases in high-intensity running during the $30-40^{\text {th }}$ minutes and the 50-60 $0^{\text {th }}$ minutes during match play (29) while the second study used GPS units and was the first to split up analysis between the forwards and backs finding a decrease in the amount of distance covered per minute between the 2 halves by approximately $10 \%(50)$. The authors of the second study reported that the differences in performance decrements among forwards and backs are likely due to the differing positional roles and contact events (50). The decreases in low-intensity and high-intensity running distances should be expected for forwards as they are exposed to more contact phases throughout a match (50). Backs were found to be able to maintain maximal speed, sprinting, and acceleration frequencies throughout a match and were less prone to fatigue than forwards (50). The dramatic decrease of high-intensity participation for backs occurred during the last 10 minutes of the game rather than throughout the match (50).

Anthropometric profiles and physiological demands have been measured for each of position. Several studies show the variances of each position and what body size and composition a player should have to optimize performance $(13,17,27,38,42,54)$. It has been observed that forwards weigh more, are taller, have a higher body fat percentage, and lean body mass than backs (1-21,23-29,31-55). At the American Collegiate level, only one study to date has focused on male rugby union players (32). It has been confirmed that like higher levels of 
rugby union, there were obvious physical and physiological differences found between the forwards and backs (32). Like other previous research, the forwards were reported to be heavier than backs with an average mass of $90.5 \pm 12.4 \mathrm{~kg}$ and $73.7 \pm 7.1 \mathrm{~kg}$ respectively (32). Forwards had an average body fat percentage of $12.6 \pm 4.2 \%$ while backs were found to be leaner at $8.8 \pm$ $2.1 \%$ (32). Interestingly enough no significant differences in height for forwards or backs were found with both groups the average height of both groups being $180 \pm 0.1 \mathrm{~cm}$ tall (32).

The heavier mass, taller height and body fat percentage have been shown to improve performance when going into contact with opposition. Scrummaging force, rucking ability, and tackling ability have all been found to correlate with body size $(9,17,38,42,54)$. However, body fat percentage has been shown to be detrimental to performance if it becomes too high $(32,17,38,42,54)$. While additional body fat may help protect the body in contact, it will also decrease speed, agility, and increases energy expenditure by making the body carry a heavier load $(5,13,27,38,55)$. It has been suggested that while there may be a decrease in mobility with higher body masses, the heavier body mass may be more important for fulfilling position requirements helping the team than hurting (27). Since forwards spend more time in contact situations and less time sprinting compared to backs, the increase fat mass may not affect forwards as much as it would for backs (27). Lean mass is more desirable for increasing performance as a lean player is more likely to have the advantage in contact due to increased momentum potential, stabilization, and inertia potentials $(17,38,42)$. Forwards have been consistently found to be display higher levels of absolute strength and power than backs $(32,55)$. One study using DEXA scans on rugby union players found large amounts of non-osseous tissue from the organs of the trunk and high levels of lean mass in the limbs of the participants in their study (27). It has been theorized that while the non-osseous tissue cannot be considered the same 
thing as lean muscle mass or have the same physiological function, the increased proportion of lean mass may improve the force and power output produced by a player (27). However, total body mass will still be a big factor when it comes to contact situations. Even if a player were to have say $5 \%$ body fat, but only weighed $75 \mathrm{~kg}$, a player with $20 \%$ body fat weighing $100 \mathrm{~kg}$ should in theory have an advantage in contact. The physical challenges each forward faces does take a toll on their body as a great deal of energy is expended during the static isometric exertion of wrestling with opponents during rucks, mauls, and tackles (14,50,55). Forwards have been reported to spend 3-4x more time in physical contact situations $(14,44)$. This increase in energy expenditure is likely the reason for forward substitutions being made earlier on in the match compared to backs (50). Regardless of position, the number of impacts sustained throughout a match has been found to cause skeletal muscle damage lead to neuromuscular fatigue (40). It has also been determined that both playing position, tackling form, and type of collision are the main factors leading to an injury $(40,49)$.

Backs benefit from the lower levels of body fat and overall body mass as their primary purpose is to evade defenders and score tries. In order to be effective in this role, they need to have sound aerobic capacities, acceleration, deceleration, and sprinting capabilities (3,4,6,8-21, 23-29,31-55). Lower levels of fat mass and total body mass make changing directions easier as there is less mass to decelerate and accelerate and improves aerobic endurance as there is less excess body mass to carry $(33,43)$. Higher levels of aerobic endurance and speed for backs have been reported at the American collegiate level as well as amateur, professional, and international levels of play. Backs have been reported to perform twice as many sprints during match-play as forwards $(11,14)$ and cover significantly more ground at higher running speeds than forwards (14). Backs have been reported to cover 1.6-2.6x more high speed running distance than 
forwards (44). Backs have also been found to accelerate and decelerate more effectively than forwards (40), but no significant differences in the number of such events were found between forwards and backs by one study (45). Forwards and backs have been reported to produce force at different isokinetic speeds, leading to differing capabilities when it comes to change of pace (40). Backs' performance may be affected by increased levels of fatigue experienced by change of direction and the accumulating muscle damage sustained from the eccentric portion of the decelerations performed (40). This high-intensity activity is important to include as backline players may not have to engage in as much physical activity as the forwards, but will still be affected due to the higher running and agility demands their positions require $(14,40,55)$.

When breaking up the forwards and backs into specific position, further body mass differences have been consistently identified. Participants from the 1998 New South Wales Super 12 rugby team's body compositions were compared for each of the different positions (17). The front row forwards (props and hookers) had an average body mass of $112.8 \mathrm{~kg}$ while the second and back row forwards (locks, flankers, and 8 man) had an average mass of $108.3 \mathrm{~kg}$ with the average mass of the backs for the same team being $89 \mathrm{~kg}$ (17). When comparing these numbers to lower levels of rugby union, the lower levels show less of a variance between the positions (17). Smaller mass differences among positions at the lower levels compared to elite levels of rugby may be caused by elite levels requiring the maximum performance from players by making sure their body size and composition is as specific as possible at each position (17). New Zealand senior A and senior B equivalents were compared and despite playing for the same club, anthropometric differences between the two levels of teams were found (17). The senior A team forwards were $98.5 \mathrm{~kg}$ compared to the $88.1 \mathrm{~kg}$ found in the senior B team forwards (17). Backs were found to have unspecified similar numbers in both A and B teams (17). However, 
between the positions of backs at the same level, there were significant differences found. The inside backs (scrumhalf and fly half) were found to have a much lower mass of $75 \mathrm{~kg}$ compared to the centers at $85.9 \mathrm{~kg}$ and outside backs (wings and fullback) at $83.4 \mathrm{~kg}$ (17). Senior A hookers weighed $89.7 \mathrm{~kg}$ while the senior A props weighed $102.8 \mathrm{~kg}$ (17). Ceri Nicholas did find some differences among positions and levels of play as well. When comparing the different positions and their respective weights, he found that props and locks were the heaviest at $103 \mathrm{~kg}$ while the back row forwards were $101 \mathrm{~kg}$ (38). The centers were the heaviest backs and the scrumhalves and fly halves were the lightest (38). After measuring a British club, he found that the senior elite players were heavier and leaner than the elite U21 teams (38). However, he did not find significant differences other than age between the first and second-class U21 teams. It has been hypothesized that the second- class players were expected to have high fitness levels causing their body composition to be similar to the first class athletes (37). Differences in stature have also been identified between position and level of play $(17,37)$. As previously noted, increased height can give a team an advantage $(13,17,38,54)$. Due to positional roles, forwards are taller than backs. Height is just as advantageous for success as body mass is for forwards as they battle for position of the ball in set-piece plays and open play $(13,17,27,38,42,54)$. Taller forward packs are more likely to win more scrums and line-outs by having increased power and drive in scrums and having a better absolute jump height in line-outs $(13,17,38,54)$. Positional height differences have been observed among forwards. Three different studies conducted in 1979, 1996, and 2003 measured the heights of players and noted the differences among positions. In 1996 found that props had an average height of $182.2 \mathrm{~cm}$, hookers were $178.8 \mathrm{~cm}$ tall, locks were $191.8 \mathrm{~cm}$ tall, and loose forwards (flankers and $8 \mathrm{men}$ ) were $186.3 \mathrm{~cm}$ tall (41). In 1979, props were found to be $180.9 \mathrm{~cm}$, hookers to be $173.5 \mathrm{~cm}$, locks to be $187.9 \mathrm{~cm}, 8$ men $189.1 \mathrm{~cm}$, and flankers $180.2 \mathrm{~cm}$ 
tall (5). A 2003 study found hookers to be the shortest at $179 \mathrm{~cm}$ and locks being the tallest at $192 \mathrm{~cm}$ tall (17). For the most part, these numbers are similar. Superior height in locks has been found to help increase absolute jumping ability giving the team with taller locks an advantage in line-outs $(17,37)$. Hookers have been found to be the shortest forward and loose forwards have been found to be significantly taller than front-row forwards (props and hookers) (41).

Of the backs, fly halves and scrumhalves have been shown to be the shortest of the backline players at $173 \mathrm{~cm}$ and $172.7 \mathrm{~cm}(17,38,54)$. These positions require endurance and agility to follow the ball, avoid tackles, and run the offense. Scrumhalves are usually bent over digging and reaching for the ball at rucks and in scrums, so being closer to the ground can be seen as an advantage. The center positions have the most physical contact among the backs and have been shown to be the tallest at $180 \mathrm{~cm}$ and $179.9 \mathrm{~cm}(17,42)$. Since centers are involved with the most tackles and rucks of the backs, being the tallest backs can definitely play to their advantage when taking part in physical events. Outside backs (wings and fullback) have not been found to be significantly shorter than centers. They have been shown to be between 179 and $179.4 \mathrm{~cm}$ tall $(17,41)$. Height can be used during receiving kickoffs, returning kicks, or catching kicks in a crowded area of the field (41). With the main roles of defending against kicks, chasing down and catching kicks, and scoring, outside backs can increase their chances of success by being taller.

Height differences can also be seen among the different levels of rugby. In general, with increasing levels of rugby, players are shown to be taller and taller (17). In 1 study, senior firstclass forward packs were found to have an average height of $186 \mathrm{~cm}$ while the senior secondclass forward pack of the same team had an average height of $181 \mathrm{~cm}$ (17). The positional differences between forwards and backs become more distinct at higher levels as well (17). This 
clearer distinction is most likely due to selecting players specifically for their height to increase success at respective positions (17).

Body fat percentage differences are also position based. Forwards in general have been found to have higher percentages of fat than backs (1-21,23-29,31-55). The right balance of fat mass and fat free mass can determine which team will outplay the other. As with height, body fat percentage is likely to decrease as the level of rugby increases (17). With more emphasis on fitness and a sound nutrition plan, international and professional rugby players generally have lower levels of body fat percentage versus players at the social and club level (17). It is important to note that while favorable characteristics for different positional roles such as height, weight, strength, power, speed, and agility seem to improve from each level of play to the next, international player selection seems to focus more on skill-level than anthropometric and physiological characteristics (47).

Props and hookers have been observed to have the highest amount of body fat percentage. Props had around $21 \%$ body fat while hookers had $19.8 \%$ body fat (5). Hookers and props make up the front-row in a scrum battling the other front-row for the ball in scrums. Since scrums are high impact events and require the front-rows of each team to press against each other as their teammates drive, it would be advantageous to have higher levels of body fat to protect themselves from the forces being placed on their bodies $(32,47)$. The 8 -man position was found to be the leanest forward at $14 \%$ body fat (5). Lower body fat percentages in 8-men can be found because they cover more ground making tackles, supporting rucks, and carrying the ball. Locks were found to have $18.8 \%$ body fat and flankers had $19.8 \%$ body fat (38). While forwards have been shown to have higher percentages of body fat than backs, they also have been shown to have a higher lean body mass (38). 
Among the backs, scrumhalves have been reported to have $14 \%$ body fat, fly halves had $8.1 \%$ body fat, centers had $12.2 \%$ body fat, wings had $11.9 \%$ body fat, and fullbacks had $13.9 \%$ body fat (5). As previously noted, backs cover significantly more ground covering kicks, trying to score against the opposition, and trying to tackle the opposition. Because they need to be faster, quicker, compete in less physical events, and cover more ground, it makes sense for them to have less body fat than forwards. Body fat percentages for backs are similar to body fat percentages found in soccer $(9.1 \%)$, field hockey $(12.4 \%)$, and track sprinters $(9.7 \%)(17)$.

Since it has been determined that forwards have higher percentages of body fat, 2 recent studies used Dual-Energy X-Ray Absorptiometry (DEXA) scans to further determine how the body fat is distributed in each group of positions $(27,33)$. Non-osseous lean tissue and bone mineral mass was also recorded from the DEXA scans. In both studies it was determined that the variations found among the position groups appear to be positional role related $(27,33)$. The larger total body mass found in forwards can be attributed to having higher non-osseous lean mass, bone mineral mass, and adipose tissue $(27,33)$. Forwards were found to have lower relative bone mineral mass and greater relative fat mass in all regions compared to backs $(27,33)$.

Forwards were also found to have lower relative non-osseous lean tissue than backs in their legs, arms, and trunk (27). Of all the players, the most mass was carried in the trunk region, followed by the legs and then arms $(27,33)$. Forwards were found to have larger proportions of mass in their arms compared to backs. Overall, forwards were found to deposit more fat in their legs compared to their arms while more bone was stored in their trunks compared to their limbs (27). Compared to the backs, more bone mineral mass was stored in the arms than trunk and legs in forwards. Backs were found to store more fat in their arms instead of their legs like the forwards do $(27,33)$. Backs also store more non-osseous lean tissue in their arms compared to forwards. A 
greater amount of lean soft tissue was found in the trunk compared to arms in backs. Both authors suggested that differences in total arm mass between forwards and backs may be due to the specific positional roles each play $(27,33)$. Forwards can use their heavier arms for rucking, fending off tackles, scrummaging, and being involved in a higher numbers of tackles. The higher amounts of bone mineral storage found in forwards' arms could be a product of adaptations from force applied during contact moments as well as muscle contractions (27). Overall, the differences in non-osseous lean tissue, bone mineral mass, and fat mass between forwards and backs found using DEXA scans can further emphasize not only the differences between positions in terms of body composition, but also how positions require specific body compositions to optimize performance $(27,33)$.

Lastly, there is evidence suggesting that body composition does not only differ between forwards and backs, but also between ethnicities. Recently, a study compared the body composition of elite Australian Rugby Union athletes by position and ethnicity using DEXA scans (54). While no significant differences were found between whole-body compositions or playing position by ethnicity, there were significant differences were found between ethnicities in regional distributions of fat and lean mass (54). Polynesian athletes showed a greater variation of fat and lean mass in their leg, periphery, and trunk regions (54). These reported differences in fat and lean mass may provide an advantage for the Polynesian players over the Caucasian players (54). Polynesian players recorded higher percentages of fat in their peripheries with lower percentages of fat in their trunk when compared to Caucasian players (54). Due to these variations, Polynesian players may have a better power to mass ratio allowing them to be more explosive and generate greater forces (42). Generating more force and having increased explosiveness would be a huge advantage for forwards in rucks, tackles, mauls, scrums, and even 
sprints (54). Previous research suggests that an association exists between regional skinfold distribution of the trunk and extremities and improvement in sprinting performance (54). Similar anthropometric differences have been found in Polynesian and non-Polynesian junior representative rugby league athletes with the advantage again going to the Polynesian athletes (54). Genetic dissimilarities among the subjects could be due to Polynesian players possessing genetic predispositions for rugby union specific physical properties giving them an advantage over non-Polynesians (54). Especially since the Caucasian and Polynesian players are both subject the same high-levels of training administered at the elite international level of rugby (54).

With the many different positions on the rugby pitch comes just as many variations of body compositions needed to perform at the highest level. Overall, forwards have higher masses, are taller, have larger percentages of body fat and lean body mass than backs $(5,13,17$, $38,42,54)$. These physical characteristics help forwards compete in physical contact while the backs' lean profiles allow them to run faster and be more agile to run around opposition $(5,13$, $17,38,42,54)$. Genetic dissimilarities may also play a role in body composition giving some ethnicities a potential advantage over other ethnicities $(13,17,54)$.

Over the last couple of decades, Rugby Union players' body compositions have been evolving to keep up with the sport. Since Rugby Union became a professional sport in 1995, teams have been doing whatever they can to maximize the performance of each player. Rule changes have also been attributed to the changes observed in rugby players along with financial support from TV contracts.

Humans have been growing taller and bigger in many different parts of the world for over 100 years (40). As a species, it is well documented that we are not only getter taller, but we are also getting fatter. As the obesity epidemic sweeps across western civilizations and other parts of 
the world, the average body mass among the general population is increasing. Rugby players are also getting heavier. Body size has been shown to be a predictor of how well a team or player will perform $(13,16,17,40,46)$. Since 1905 , rugby players' body mass has increased greatly, especially in the past 45 years $(16,40)$. From 1905-1974 the average rugby player weighed $87.8 \mathrm{~kg}$ (40). From 1975-1999 the average rugby player's mass increased to $95.1 \mathrm{~kg}(40)$. By 2007, the average rugby players mass had increased to $99.35 \mathrm{~kg}$ (46). Most recently, a study published in 2017 measured body composition in professional English rugby union players throughout a competitive season (33). Of the 35 participants, the average mass was reported to range between $101.55-102.5 \mathrm{~kg}$ throughout the season presenting a slight increase within the past decade (33). Body size has been shown to be a predictor of how well a team or player will perform $(4,6,7,9,11)$. Teams with larger body masses have been shown to have a better chance of winning a world cup (11). As stated before, forwards have much heavier body masses when compared to backs (1-21,23-29,31-55). A larger body mass is essential for forwards due to their involvement in contact situations $(5,17,20,27,38,42,46)$. Forwards are more involved in tackling, rucking, mauling, and scrums. These contact aspects of rugby involve battling the opposition for possession of the ball or from gaining meters. An increase in body mass can be beneficial since force output equals mass multiplied by acceleration (27). Therefore, if a player has a larger body mass, it is likely that they will be able to produce a larger force upon impact. However, if the mass is too large, there may be a negative impact on velocity production decreasing acceleration. Players need to make sure they are at a weight that allows them to perform effectively. From 2002-2011, forwards' body mass has increased by $1.9 \mathrm{~kg}$ per decade (20). Since the first World Cup in 1984, forwards' body mass has been found to increase by $0.33 \mathrm{~kg}-1.34 \mathrm{~kg}$ from World Cup to World Cup compared to the $0.3 \mathrm{~kg}-1.46 \mathrm{~kg}$ increase found in backs (46). Since backs are 
required to cover more a larger area of the field, it makes sense for the backs to have a lower body mass than forwards. However, backs average body mass has also been shown to be increasing throughout the years $(16,20,27,40,46)$. Backs have increased by an average of $2.4 \mathrm{~kg}$ per decade (11). Increased mass for backs can also be attributed to an increase in contact situations. In general, the number of tackles and rucks in a Rugby Union game has increased by 4-fold over the past 30 years (46). Backs are expected to support each other and ruck to maintain possession of the ball while the forwards work their way to the breakdown. Backs are also expected to make one-on-one tackles in the open field. Speed and agility are big factors when it comes to beating an opponent. Because backs are lighter, they have an advantage over forwards in the open field. Backs also have a lot more space to cover leading to a lot more running. The overall intensity of Rugby Union has increased as the speed of play, number of tackles and rucks, and longer duration of the game $(20,46)$. Overall, an increase in player's mass and BMI should be due to an increase in lean mass rather than fat mass $(16,20,27,40,46)$. Due to the intensity demands of rugby, the more weight carried may have a negative effect on player performance $(16,45)$. The goal of players and coaches should be to increase lean body mass as it may increase power, speed, and strength (40). There is an inverse relationship between the ranking of BMI and ability to cover distances via walking or running throughout a match (40).

Of course, different positions have shown larger increases in mass compared to others. One study quantified the transformations in each participating players' body composition over the course of the 2002-2012 seasons (20). Both the forwards and backs in general were found to have increasing body mass over the decade observed. Among the forwards, the second row has shown the largest increase in body mass by an average of $2.7 \mathrm{~kg}$ per decade (20). Props have also shown increases in body mass over the years by about $1.5 \mathrm{~kg}$ per decade (20). Hookers did not 
show a big variation at all with having the same average body mass throughout the decade (20). The back row like the props also showed a $1.5 \mathrm{~kg}$ per decade increase in body mass (20). Of the backs, the largest increase in body mass throughout the decade in the study conducted by Fuller et al. occurred in fly halves at $2.9 \mathrm{~kg}$ per decade. Scrumhalves were found to have around a $2 \mathrm{~kg}$ increase per decade while the centers showed a $1.3 \mathrm{~kg}$ increase (20). The back three were found to have $2.5 \mathrm{~kg}$ increase in body mass per decade (20).

Along with increases in body mass, Rugby Union players have been getting taller as well (1-21,23-29,31-55). As previously mentioned, height has been shown to be advantageous for certain positions in Rugby Union. Among all of the World Cup finalists, semifinalists, and quarterfinalists were significantly taller than backs of other teams (20). Teams who have won the World Cup have had backs with the height of $182.4 \mathrm{~cm}$ compared to the rest of the competitors with a height of $180.9 \mathrm{~cm}$ (46). Similar trends were seen for forwards but did not reach statistical significance (46). While forwards did not reach statistical significance, the winning teams' forwards were taller than all other teams $(40,46)$. Rugby Union players have been growing taller at the rate of about $1.0 \mathrm{~cm}$ per decade; about the same rate as the general population of Australia as of $2001(40)$.

Another study of elite rugby union players focusing on English teams reported a $1.4 \mathrm{~cm}$ and $1.3 \mathrm{~cm}$ increase in height over the course of the 10-year study for forwards and backs respectively (20). The reported increases in height reported were found to be higher than $0.3 \mathrm{~cm}$ increase in height for the average male aged 25-34 in the UK (20). From 1905-1974, the average height for all players was $180.4 \mathrm{~cm}$ (40). From 1975-1999 the average height had increased to $184 \mathrm{~cm}$ (40). The average height of all players who participated in the 2007 World Cup had risen to $185 \mathrm{~cm}(46)$. 
Different positions have seen greater increases in height when compared to others. Of the forwards, props showed the biggest increase in height. There are both positives and negatives becoming taller for props. In the scrums, larger heights actually can work against props if their neck strength and flexibility is not adequate (20). Since props main role is to stabilize and drive scrums, it is imperative that they are able to get low enough to have an advantage over their opponent. If they cannot get low enough or their neck is not strong or flexible enough to allow them to get a lower body position and maintain it, they will not be as effective in a scrum. For lineouts, height is also advantageous for props. Increased height has shown to give props an advantage by allowing them to lift the locks up higher (20). Props have been reported to have an increase in height of $3.1 \mathrm{~cm}$ per decade, well above the average general population height increase reported both general population increases of $0.3 \mathrm{~cm}$ and $1 \mathrm{~cm}$ per decades $(20,40)$. For backs, the biggest increase in height was seen at the fly-half position (20). From 2002 to 2011, the average height of fly-halves increased by $4.6 \mathrm{~cm}$ (20). Other positions also showed increases in overall height over the past decade. Hookers increased by $0.8 \mathrm{~cm}$, back row players had a $1.1 \mathrm{~cm}$ increase in height, centers increased by $0.8 \mathrm{~cm}$, and back-three positions increased height by $1.1 \mathrm{~cm}(40)$.

Recent changes in the body composition of rugby union players have been evolving towards a leaner body. From 1975-1999, rugby union players' body types have developed from endomorphic to mesomorphic (40). Forwards have also shown are significant change from being ectomorphic to mesomorphic (40). This increase from ectomorphic and endomorphic in rugby union players from 1975-1999 shows an increase twice as fast as the increases in the general population (40). 
Several factors can also be considered when trying to put a reason behind the changes of body composition of rugby union players. Professional sports can definitely be considered as a money-driven industry (20). Top-level players can usually be able to support themselves or their families based on the salaries they earn from being a professional athlete. It should come as no surprise that the professionalization of the sport in 1995 led to the sport itself becoming more competitive as players could now make a living off playing the sport they love (39). Countries and now team owners now search for the best of the best as they look to win championships. The intensity of rugby union has been increasing from season to season due to increasing player size, conditioning, and rule changes $(40,46,54,55)$. Many professional teams provide nutritional planning and consistent strength and conditioning programs for their athletes. These resources can be a possible factor in the increasing lean body builds in rugby union athletes $(2,16,20,27,40,46)$. Without needing to hold careers outside of rugby, professional athletes are able to dedicate more time training with professional strength and conditioning coaches to improve performance. It is likely that depending on each player's position; the conditioning coaches and nutritionists will individualize programs for each player targeting certain goals or outcomes to optimize each athlete's performance $(16,20,27,40,46)$.

Positional roles and rule changes can also be other factors to consider in the evolution of body composition among Rugby Union players. As each position has its own specific role, each position will require a different body size to be the most effective. Rule changes implemented in 2000 along reduced the number of scrums in Rugby Union Super 12 competition by $20 \%$ (20). If fewer scrums are taking place, then the desired body types of forwards that may increase scrimmaging performance may become less desirable. An example would be not needing such a heavy front-row in the scrums (20). While the amount of scrimmaging may have become 
reduced, an increase in the number of tackles or rucks per match has been reported to increase by 4-fold in the past 30 years (46). Contact phases are still a huge part of rugby union and allow the larger teams to have the advantage Previous research has also reported an increase in the number of rucks from the 5 and 6 nation tournaments over the years (46). They found that in 1988 there were 62.3 rucking events per game compared to the 134.3 rucking events per game in 2002 (46). It's no wonder that players have become larger with the amount of physical confrontations each game requires.

As coaches are searching for their next superstar to add to their roster, an increase in the world population can make finding that star more likely. Obviously, as the world turns the world population grows with the number of babies being born outnumbering the number of people passing on. As Rugby Union's international marketing increases, more of the world's population may be grow up playing rugby from a younger age. America for example, has seen a large increase in the number of Rugby Union programs at not only the high-school level, but also at the middle-school age. Rookie Rugby is a program targeting younger aged kids to begin developing and playing rugby from early on. By having youth athletes partaking in rugby at a younger age, the number of skilled players will increase allowing for more competition among top-level programs to recruit the best of the best. Once these young players continue to climb the ladder of age and level of rugby, they will likely be developed and specialized to positions based on their anthropometric characteristics and skill-level. Developing and recruiting an increased number of athletes for top-level programs may increase the number of players with the specific body composition and anthropometric profile required to perform at an optimum level.

While it is important for coaches, players, nutritionists, and strength coaches to know the ideal anthropometric qualities and physiological demands of rugby union to optimize player 
performance, it's just as important for those individuals to be aware any possible changes that may occur both physically and physiologically throughout a competitive season. Recently, there have been a few more studies identifying changes in the body composition of male rugby players. One study from 1993 (28) and another from 2005 (21) measured players' height, body mass, and sum of 7-skinfolds during each period of the season. A $3^{\text {rd }}$ study published in by 2005 focused on a Super 12 rugby union franchise from 1999-2003 measuring each players' body mass and sum of 7-skinfolds each year (18). Each year was divided into 4 different phases consisting of a pre-season, Super 12 match play, club match play, and off-season (18). Preseason and Super 12 match play had a higher training load compared to the club match play and off-season periods of the year (18). Body composition of each player was assessed 705 times throughout the study (18). A $4^{\text {th }}$ study published in 2011 measured changes in 20 elite rugby league players throughout the course of a season using DEXA scans during the pre-season, midseason, and post-season (25). A $5^{\text {th }}$ study published in 2012 used similar methods as the 2011 study but with 37 players during the 2009 Australian National Rugby League season (24). Participants from the 2012 study underwent a DEXA scan during the pre-season, mid-season, and post-season of the 2009 season and during the pre-season of the 2010 season with professional rugby league players (24). Most recently, a 2017 study focused on 1 English Premiership Rugby Union team also using DEXA scans during the pre-season, mid-season, and post-season to identify changes in body composition (33).

The last study identified to measure changes in body composition of rugby union players over time measured the sum of 7-skinfold sites and weighed players to identify changes in body mass (1). 
Among the 7 studies reviewed, varying patterns of change for body composition were identified. Player body composition changes will vary throughout the season due to several factors such as the amount of playing time, time missed due to injury, time spent travelling, time training outside of match play, dietary behaviors, and possible illnesses may affect players differently causing variation among each individual (18). Significant decreases in the sum of skinfolds were identified by throughout the 1991-92 season for English professional rugby union players (28). Of the changes, it was reported that the largest decreases took place during the offseason and first half of the season (28). The sum of skinfolds was found to remain rather consistent during the second half of the season (28).

Between the 1999-2003 seasons, forwards were found to experience a 5.3\% decrease in sum of skinfolds from the pre-season to the Super 12 match play (18). During the club season, forwards showed a 7.8\% increase in sum of skinfolds (18). However, body mass was only found to vary by about $1.6 \%$ during the Super 12 matches in the same season, indicating that player body composition changes did occur during 1 season (18). From Super 12 season to Super 12 season, player's total body mass only varied by about $2.1 \%$ (18). Player's with a lower skinfold sum were more likely to show a larger increase in lean mass when exposed to heavy training levels (18). Those with a higher skinfold sum were the opposite showing larger decreases in total body mass when exposed to higher training levels while those with a middle skinfold sum were more likely to maintain a consistent total body mass (18). Of all the subjects, regardless of position, there was around a $1.5 \%$ decrease in lean body mass during the first two years of participating in the Super 12 team program (18). These decreases in lean body mass were due to an increased number of sum of 7-skinfolds and a decreased amount of lean mass (18). However, between the first two seasons and the third season all players were found to experience an 
increase in lean body mass by decreasing the sum of skinfolds and increasing lean mass(18). The increase in lean body mass was found to be about $0.5 \%$ (18). The greater number of lean mass changes over all three years occurred during the club match play leading to a fluctuation of body composition each year (18). It has been suggested that players should try to maintain the same body composition from year to year and focus on improving it allowing players' body composition to build up for a larger improvement over years instead of having to improve it each season just to get back to where they started (18). Among each individual player, only small differences in body mass and sum of skinfolds were found for both forwards and backs throughout the study. Subjects were found to have about a $2 \%$ decrease in body mass, $1 \%$ increase in sum of skinfolds, and a clear decrease in lean mass index from 1999-2003 (18). Players recruited earlier in 1999 were more likely to be leaner compared to those who would be added to the team in 2003 (18). Although it seems that the players involved in this study were developing slightly poorer body compositions, player skill level may outweigh the importance of body composition when considering players for selection (18).

Results from the $7^{\text {th }}$ study mentioned indicated that there was a decrease in sum of skinfolds from the 2007-2008 season and a slight increase between the 2008-2009 season (1). Players were found to have an increased lean mass index and body mass from year to year as well (1). The findings from this study are important because they show that professional players are able to continue to progress in terms of improving body composition from season to season rather than experiencing fluctuating levels of body fat $(1,4)$.

The 2005 of amateur rugby league players indicated that there was no change for player height or mass at any point of the season (21). Slight decreases in sum of skinfolds were found from the offseason to pre-season while players' sum of skinfolds slightly increased from the pre- 
season to mid-season and again from the mid-season to post-season (21). Similar to the 2005 findings, the 2011 of 20 elite rugby league players reported a significant increase in fat-mass and body fat percentage during the $2^{\text {nd }}$ half of the season along with a corresponding significant decrease in lean-mass (25). No change in body mass was found throughout the season (25). While a 2012 study of professional rugby league players did find a decrease in lean-mass over the course of the season, no increases in fat mass were found contradicting previous research (21,25). A 2012 and 2017 of professional rugby league and professional rugby union players respectively did not find any significant changes in body mass throughout the entire competitive season supporting findings from previous research $(21,25,28)$. The 2017 study did report a significant decrease in lean-mass for both forwards and backs during the second-half of the season (33). Forwards also displayed significant increases in fat-mass from the pre-season to post-season while backs were found to have significantly increased levels of fat-mas during both halves of the season (33). Corresponding with the increased levels of fat-mass, forwards and backs were found to have significantly increased levels of body fat percentage during the firsthalf of the season with backs also showing significant increases in the second-half of the season as well (33).

Unfortunately, very few studies have attempted to track changes in physiological characteristics such as speed, maximal aerobic power, anaerobic power, agility, and mobility over the course of a competitive season in rugby union players. In fact, to the authors' knowledge, there is only one study published in 1993 that has set out to track changes in several of these variables using 23 participants from the England national rugby union team (28). Another study conducted in 2005 measured both anthropometric and physiological changes over a season with amateur rugby league players (21). While neither study measured player mobility 
over the course of a season, 1 study from 2014 has (53). Twelve elite U19 rugby league players perform Functional Movement Screenings during the pre-season, mid-season, and post-season. In addition to mobility, changes player speed, upper and lower body strength, power were also analyzed (53).

A variety of findings have been reported in regards to changes in speed throughout a season. The 1993 study of international rugby union players reported a significant increase in speed over the course of the 1990-1991 season for the 30m sprint (28). Players were found to be at their fastest during the last testing session (28). Interestingly enough, the largest change in speed for the backs occurred during the off-season while the forwards saw the largest increase in speed during the $1^{\text {st }}$ half of the playing season (28). No significant changes in speed were found during the 2005 study of amateur rugby league players (21). The fastest times for all 3 sprint distances were recorded during the final testing period (21). The 2014 of elite U19 rugby league players did find significant decreases for $10 \mathrm{~m}$ and $40 \mathrm{~m}$ sprints times during the $1^{\text {st }}$ half of the season but no significant changes in speed were reported during the second half of the season (53).

Anaerobic Power has been measured several different ways for rugby union and rugby league players. One study has used a Yardstick vertical jump device (21) to measure players' maximal jump heights while another had participants perform a countermovement jump test (53). A $3^{\text {rd }}$ study used a $20 \mathrm{~m}$ high-intensity shuttle-run test estimating maximal accumulated oxygen deficit (28). No significant changes were found while using the $20 \mathrm{~m}$ high-intensity shuttle-run test (28). Significant increases in power for amateur rugby league players were found from the pre-season to mid-season and significantly lower results from the mid-season to postseason (21). Elite U19 rugby league players were reported to experience a significant increase in 
power during the $1^{\text {st }}$ half of the season and remain relatively stable during the $2^{\text {nd }}$ half of the season (53). A 4th study assessed changes in strength, power, and steroid hormones in 32 professional rugby union players over the course of a season (2). Upper-body power was measured via a bench-throw test while lower body power was calculated using a jump squat. Each test was administered up to 5 times throughout a season (2). Overall, a significant decrease in both upper body and lower body power by 3.3 and $3.4 \%$ respectively were found (2). A $5^{\text {th }}$ study published in 2015 concluded that with the appropriate concurrent training structure and execution, rugby union players can increase both power and strength during the early portions of the season (23). The gains in both strength and power may also be maintained or slightly decreased as the season progresses but still provide benefits to the participating players (23). A $6^{\text {th }}$ study also supports the notion that strength can be improved in rugby union players from one year to the next (1). Players were found to increase their lean mass index via decreased sum of skinfolds and increased levels of strength from each year they participated in the teams' training program (1). Gains in strength and muscle mass were reported despite the participants being professional rugby union players and considered to already high levels of fitness (1).

Two studies have used the $20 \mathrm{~m}$ multistage shuttle-run test to estimate changes in players' estimated aerobic power throughout the season. One found a significant increase in aerobic power throughout the course of the season with a steady increase during the off-season, no improvement during the $1^{\text {st }}$ half of the season, and a non-significant decline during the $2^{\text {nd }}$ half of the season (28). Similarly the second study found the largest increase in aerobic power to occur during the off-season to pre-season phase, a smaller increase in aerobic power during the $1^{\text {st }}$ half of the season and a decrease during the $2^{\text {nd }}$ half (21). Despite the decrease in the latter half of the 
season indicated by both studies, the post-season aerobic power scores were still higher than the off-season scores (21).

To the authors' knowledge, only one study has tried to determine if agility varies throughout a competitive season. Participants performed 2 attempts of the L-drill agility test during the off-season, pre-season, mid-season, and post-season and were found to display an insignificant $2 \%$ increase in agility throughout a competitive season (21).

Mobility has also been found to stay rather consistent throughout a competitive rugby league season courtesy of a study conducted in 2014 with 12 elite U19 rugby league players (53). Rugby union players who performed poorly on a pre-season FMS test have been found to beat a higher risk for injury than those who scored higher (49). The Active Straight Leg Raise (ASLR) component test has been found to be the most sensitive test for identifying those at risk for injury (49), but has also been found to have the greatest chance of being influenced by measurement error (53). While players showed increases in speed, strength, and power during the $1^{\text {st }}$ half of the season, no significant differences were found for any of the 12 FMS component tests indicating that players' may improve in different physiological characteristics despite not increasing their mobility (53).

Throughout a competitive season, rugby players are likely to experience changes in body composition and physiological capacities. Of the reviewed literature, the general consensus is that players may experience a decrease in fat-mass earlier in the season with simultaneous increases in lean-mass as training and conditioning loads will likely be the focus of training sessions $(16,21,28,33)$. These positive body composition adaptations may help players' performance on the pitch as the decreased fat-mass and increased lean-mass may help improve physiological factors such as maximal aerobic capacity, speed, and power $(21,23,28,53)$. 
However, accumulating training and match loads, possible injuries, decreased emphasis of conditioning during training, increased emphasis on team strategy, and overall fatigue may lead to players experiencing increasing levels of fat-mass and decreased levels of fat-free mass during the latter-half of the season $(16,21,24,25,33)$. These negative compositional adaptations may lead to players' aerobic capacities, and power to decrease $(2,21)$. Although, there is some evidence suggesting that any improvements in power and speed during the pre-season may be maintained during the second-half of the season $(28,53)$.

\section{Summary}

Rugby union is a physical sport requiring short periods of high-intensity sprinting, tackling, rucking, scrumming, and mauling followed by longer periods of low-intensity jogging, walking, or running as players re-position themselves for the next phase of offensive or defensive play. Similar to most sports, the physiological demands of the sport will dictate what anthropometric characteristics will benefit the team based on the differing positions. Generally speaking, forwards may not need to cover as much distance, sprint, or defend in the open field as much as backs, but they will benefit from being heavier, stronger, and more powerful based on their positional roles. Backs should aim to be leaner, agile, fast, yet still ready for contact as they will have the ball in open space for more often trying to gain meters and work to score.

Fatigue will affect players of the course of the season with accumulating training and match loads. Teams should focus on allowing their players adequate rest and provide different recover methods to avoid losing players to injuries later on as the season progresses. The overall gains of off-season training may diminish throughout the season as less time will likely be spent on fitness and a greater emphasis is placed on tactical play or physical fatigue sets in. With the 
possible decreasing levels of anaerobic power, aerobic power, players may also experience a decrease in lean-mass and increase in fat-mass as the season progresses. 


\section{References}

1. Appleby, B, Newton, R, and Cormie, P. "Changes in Strength over a 2-Year Period in Professional Rugby Union Players.” Journal of Strength and Conditioning Research 26.9 (2012): 2538-2546. Print.

2. Argus, C, Gill, N, Keogh, J, Hopkins, W, and Beaven, M. "Changes in Strength, Power, and Steroid Hormones During a Professional Rugby Union Competition.” Journal of Strength and Conditioning Research 23.5 (2009): 1583-1592. Print.

3. Austin, D, Gabbett, T, and Jenkins, D. "The Physical Demands of Super 14 Rugby Union." Journal of Science and Medicine in Sport 14 (2011): 259-263. Print.

4. Austin, D, Gabbett, T, and Jenkins, D. "Repeated High-Intensity Exercise in Professional Rugby Union.” Journal of Sports Science 29 (2011): 1105-1112.

5. Bell, William. "Body Composition of Rugby Union Football Players." British Journal of Sports Medicine 13 (1979): 19-23. Print.

6. Cahill, N, Lamb, K, Worsfold, P, Heady, R, and Murray, S. "The Movement Characteristics of English Premiership Rugby Union Players.” Journal of Sports Science 31 (2013): 229237.

7. Comfort, C, Graham-Smith, P, Matthews, M, and Bamber, C. "Strength and Power Characteristics in English Elite Rugby League Players." Journal of Strength and Conditioning Research 25.5 (2011): 1374-1384. Print.

8. Coughlan, G, Green, B, Pook, P, Toolan, E, O’Connor, S. "Physical Game Demands in Elite Rugby Union: A Global Positioning System Analysis and Possible Implications for Rehabilitation." Journal of Orthopaedic and Sports Physical Therapy 41.8 (2011). Online.

9. Crewther, B, McGuigan, M, Gill, N. "The Ratio and Allometric Scaling of Speed, Power, and Strength in Elite Male Rugby Union Players.” Journal of Strength and Conditioning Research 25.7 (2011): 1968-1975. Print.

10. Cunniffe, B, Proctor, W, Baker, J, and Davies, B. "An Evaluation of the Physiological Demands of Elite Rugby Union Using Global Positioning System Tracking Software." Journal of Strength and Conditioning Research 12.4 (2009): 1195-1203. Print.

11. Cunningham, D, Shearer, D, Drawer, S, Eager, R, Taylor N, Cook, C, Kilduff, L. "Movement Demands of Elite U20 International Rugby Union Players." PLoS ONE 11.4 (2016).Online.

12. Deutsch, M, Kearny, G, and Rehrer, N. "Time-Motion Analysis of Professional Rugby Union Players During Match-Play.” Journal of Sports Science 25 (2007): 461-472. Print. 
13. Delahunt, Eamonn, Byrne, Risteard, Doolin, Rachel, McInerney, Rory, Ruddock, Ciaran, and Green, Brian. "Anthropometric Profile and Body Composition of Irish Adolescent Rugby Union Players Aged 16-18." Journal of Strength and Conditioning Research 27.12 (2013): 3252-3258. Print.

14. Dubois, R, Paillard, T, Lyons, M, McGrath, D, Maurelli, O, and Prioux, J. "Running and Metabolic Demands of Elite Rugby Union Assessed Using Traditional, Metabolic Power, and Heart Rate Monitoring Methods." Journal of Sports Science and Medicine 16 (2017): 84-92. Print.

15. Durandt, J, du Toit, S, Borresen, J, Hew-Butler, T, Masimia, H, Jakoet, I, and Lambert, M. "Fitness and Body Composition Profiling of Elite Junior South African Rugby Players.” South African Journal of Sports Medicine 18.2 (2006): 38-45.Print.

16. Duthie, G, Hopkins, W, Livingstone, S, and Hooper, S. “Anthropometry Profiles of Elite Rugby Players: Quantifying Changes in Lean Mass.” British Journal of Sports Medicine 40 (2006): 202-207. Print.

17. Duthie, G, Pyne, D, and Hooper, S. “Applied Physiology and Game Analysis of Rugby Union.” Journal of Sports Medicine 33.13 (2003): 973-991. Print.

18. Duthie, G, Pyne, D, and Hooper, S. "Time Motion Analysis of 2001 and 2002 Super 12 Rugby." Journal of Sports Science 23 (2005): 523-530. Print.

19. Duthie, G, Pyne, D, Marsh, D, and Hooper, S. "Sprint Patterns in Rugby Union Players During Competition”. Journal of Strength and Conditioning Research 20 (2006): 208 214. Print.

20. Fuller, Colin, Taylor, Aileen, Brooks, John, and Kemp, Simon. "Changes in the Stature, Body Mass, and Age of English Professional Rugby Players: A 10-Year Review.” Journal of Sports Sciences 31.7 (2013): 795-802. Print.

21. Gabbett, T. "Changes in Physiological and Anthropometric Characteristics of Rugby League Players During a Competitive Season." Journal of Strength and Conditioning Research 19.2 (2005): 400-408. Print.

22. Gabbett, T. "Quantifying the Physical Demands of Collision Sports: Does Microsensor Technology Measure What it Claims to Measure?" Journal of Strength and Conditioning Research 27.8 (2013): 2319-2322. Print.

23. Gannon, E, Stokes, K, and Trewartha, G. "Strength and Power Development in Professional Rugby Union Players over a Training and Playing Season.” International Journal of Sports Physiology and Performance (2015). Online. 
24. Georgeson, E, Weeks, B, McLellan, C, and Beck, B. "Seasonal Change in Bone, Muscle, and Fat in Professional Rugby League Players and it's Relationship to Injury: A Cohort Study." BMJ Open 2 (2012) Online.

25. Harley, J, Hind, K, O’Hara, J. “Three-Component Body Composition Changes in Elite Rugby League Players During a Super League Season, Measured by Dual-Energy X-Ray Absorptiometry." Journal of Strength and Conditioning Research 25.4 (2011): 1024-1029. Print.

26. Hartwig, T, Naughton, G, Searl, J. "Motion Analyses of Adolescent Rugby Union Players: A Comparison of Training and Game Demands." Journal of Strength and Conditioning Research 25.4 (2011): 966-972. Print.

27. Higham, D, Pyne, D, Anson, J, Dziedzic, C, and Slater G. "Distribution of Fat, Non- Osseous Lean and Bone Mineral Mass in International Rugby Union and Rugby Sevens Players.” International Journal of Sports Medicine (2013). Online.

28. Holymard, D, Hazeldine, R. "Seasonal Variation in the Anthropometric and Physiological Characteristics of International Rugby Union Players. " Science and Football II: Proceedings of the Second World Congress of Science and Football (1993): 21-26. Print.

29. Jones, M, West, D, Harrington, B, Cook, C, Bracken, R, Shearer, D, and Kiduff, L. "Match Play Performance Characteristics that Predict Post-Match Creatine Kinase Responses in Professional Rugby Union Players." BMC Sports Science, Medicine, and Rehabilitation 38.6 (2014). Online.

30. Kaminsky, L. (2014). ACSM's Health-Related Physical Fitness Assessment Manual (4 ${ }^{\text {th }}$ ed.) Philadelphia, PA: Lippincott Williams \& Wilkins.

31. Lacome, M, Piscione, J, Hager, J, and Bourdin, M. “A New Approach to Quantifying Physical Demand in Rugby Union.” Journal of Sports Science 32 (2014): 290-300. Print.

32. LaMonica, M, Kukuda, D, Miramonti, A, Beyer, K, Hoffman, M, Boone, C, Tanigawa, S, Wang, R, Church, D, Stout, J, and Hoffman, J. "Physical Differences Between Forwards and Backs in American Collegiate Rugby Players." Journal of Strength and Conditioning Research 30.9 (2016): 2382-2391. Print.

33. Lees, M, Oldroyd, B, Jones, B, Brightmore, A, O’Hara, J, Barlow, M, Till, K, and Hind, K. "Three-Compartment Body Composition Changes in Professional Rugby Union Players Over One Competitive Season: A Team and Individualized Approach." Journal of Clinical Densiometry: Assessment \& Management of Musculoskeletal Health 20 (2017): 50-57. Print. 
34. Mayorga-Vega, D, Aguilar-Soto, P, and Viciana, J. "Criterion-Related Validity of the 20-MS Shuttle Run Test for Estimating Cardiorespiratory Fitness: A Meta-Analysis.” Journal of Sports Science and Medicine 14 (2015): 536-547. Print.

35. McLaren, S, Weston, M, Smith, A, Cramb, R, and Portas, M. "Variabilitiy of Physical Performance and Player Match Loads in Professional Rugby Union." Journal of Science and Medicine in Sport (2015). Online.

36. McLean, D. "Analysis of the Physical Demands of International Rugby Union.” Journal of Sports Science 10 (1992): 285-296. Print.

37. Nakamura, F, Pereira, L, Moraes, J, Kobal, R, Kitamura, K, Cal Abad, C, Teixeira Vaz, L, And Loturco, I. "Physical and Physiological Differences of Backs and Forwards from the Brazilian National Rugby Union Team.” Journal of Sports Medicine and Fitness (2016). Online.

38. Nicholas, Ceri. "Anthropometric and Physiological Characteristics of Rugby Union Football Players.” Journal of Sports Medicine 6 (1997): 375-396. Print.

39. Olds, T. "The Evolution of Physique in Male Rugby Union Players in the Twentieth Century” Journal of Sports Sciences 19 (2001): 253-262. Print.

40. Owen, S, Venter, R, du Toit, S, and Kraak, W. "Acceleratory Match-Play Demands of a Super Rugby Team over a Competitive Season.” Journal of Sports Sciences (2015). Online.

41. Quarrie, K, Handcock, P, Waller, A, Chalmers, D, Toomey, M, and Wilson, B. "The New Zealand Rugby Injury and Performance Project. III. Anthropometric and Physical Performance Characteristics of Players." British Journal of Sports Medicine 29.4 (1995): 263-270. Print.

42. Quarrie, K, Handcock P, Toomey, M, and Walter, A. "The New Zealand Rugby Injury and Performance Project. IV. Anthropometric and Physical Performance Comparisons between Positional Categories of Senior A Rugby Players." British Journal of Sports Medicine 30 (1996): 53-56. Print.

43. Quarrie, K, Hopkins, W, Anthony, M, and Gill, N. "Positional Demands of International Rugby Union: Evaluation of Player Actions and Movements." Journal of Science and Medicine in Sport 16 (2013): 353-359. Print.

44. Roberts, S, Trewartha, G, Higgitt, R, El-Abd, J, and Stokes, K. "The Physical Demands of Elite English Rugby Union.” Journal of Sports Science 26 (2008): 825-833. Print.

45. Reardon, C, Tobin, D, Delahunt, E. “Application of Individualized Speed Thresholds to Interpret Position Specific Running Demands of Elite Professional Rugby Union: A GPS Study." PLoS ONE 10.7 (2015). Online. 
46. Sedeaud, Adrien, Schipman, Julien, Tafflet, Muriel, Hager, Jean-Philippe, and Toussaint, Jean-Francois. "How they won Rugby World Cup through Height, Mass, and Collective Experience." British Journal of Sports Medicine (2012): 1-5. Online.

47. Smart, D, Hopkins, W, Gill, N. "Differences and Changes in the Physical Characteristics of Professional and Amateur Rugby Union Players. ” Journal of Strength and Conditioning Research 27.11 (2013): 3033-3044. Print.

48. Suarez-Arrones, L, Portillo, L, Gonzalez-Rave, J, Munoz, V, and Sanchez, F. "Match Running Performance in Spanish Elite Male Rugby Union using Global Positioning Software." Isokinetic Exercise Science 20 (2012): 77-83.

49. Tee, J, Klingbiel, J, Collins, R, Lambert, M, and Coopoo, Yoga. "Preseason Functional Movement Screen Component Tests Predict Severe Contact Injuries in Professional Rugby Union Players.” Journal of Strength and Conditioning Research 30.11 (2016): 3194-3203. Print.

50. Tee, J, Lambert, M, and Coopoo, Y. "Impact of Fatigue on Positional Movements During Professional Rugby Union Match Play" International Journal of Sports Physiology and Performance (2016). Online.

51. Van Gent, Maya and Spamer, Emanuel. "Comparisons of Positional Groups in Terms of Anthropometric, Rugby-Specific Skills, Physical and Motor Components among U 13, U 16, U 18, and U 19 Elite Rugby Players." Journal of Kinesiology 37 (2005):50-63. Print.

52. Venter, R, Opperman, E, and Opperman S. "The Use of Global Positioning System (GPS) Tracking Devices to Assess Movement Demands and Impacts in Under-19 Rugby Union Match-Play." Afr Journal of Physical Health Education, Recreation, and Dance 17 (2011): 1-8.

53. Waldron, M, Gray, A, Worsfold, P, and Twist, C. "The Reliability of Functional Movement Screening and In-Season Changes in Physical Function and Performance Among Elite Rugby League Players.” Journal of Strength and Conditioning Research 30.4 (2014): 910-918. Print.

54. Zemski, Adam, Slater, Gary, Broad, Elizabeth. "Body Composition Characteristics of Elite Australian Rugby Union Athletes According to Playing Position and Ethnicity.” Journal of Sports Sciences (2015): 1-8. Print.

55. Ziv, G and Lidor, R. "On-Field Performances of Rugby Union Players-A Review." Journal of Strength and Conditioning Research 30.3 (2015): 881-892. Print. 
APPENDIX A:

INITIAL MEETING QUESTIONAIRE

Initial Meeting Questionnaire

\begin{abstract}
Changes in Anthropometric and Physiological Characteristics of Male Rugby Union
Players during a Competitive Season
\end{abstract}

4-Digit Subject \#:

Age:

Date:

Circle $\mathrm{Y}$ for "Yes" for $\mathrm{N}$ for "No" or fill in a response on the lines provided:

1. Are you able to understand and read English? $\mathrm{Y}$ N

2. Are you currently an active member of the Illinois State Men's Rugby Club? Y N

3. Are you currently being treated for any musculoskeletal injuries? $\mathrm{Y} N$

4. How many years have you been playing the sport of rugby union?

5. What is the highest level of rugby union that you have played at? 
6. What position(s) do you play?

7. Do you currently participate in cardiovascular training outside of team training sessions?

Y N

1. If yes, how often?

2.

3. If yes, how many minutes does each session usually last?

8. Do you currently participate in resistance training outside of team training sessions?

$$
\text { Y N }
$$

1. If yes, how often?

2.

3. If yes, how many minutes does each session usually last?

9. Do you currently participate in any other forms of training outside of team training sessions that may cause an improvement in agility, speed, muscular power, mobility, body composition, or cardiovascular conditioning?

1. If yes, please specify what types of training you participate in:

2. If yes, please specify how many minutes each training session lasts: 
10. Have you previously experienced any injuries that have kept you from participating in any physical activity in your past? $\mathrm{Y} N$

1. If yes, please specify what injury:

2. If yes, please specify how long you were held from participation in physical activity: 


\section{APPENDIX B:}

\section{PHYSICAL ACTIVITY READINESS QUESTIONAIRE}

Physical Activity Readiness Questionnaire - PAR-Q (revised 2002)

\section{PAR-Q \& YOU}

(A Questionnaire for People Aged 15 to 69)

Regular physical activity is fun and healthy, and increasingly more people are starting to become more active every day. Being more active is very safe for most people. However, some people should check with their doctor before they start becoming much more physically active.

If you are planning to become much more physically active than you are now, start by answering the seven questions in the box below. If you are between the ages of 15 and 69, the PAR-Q will tell you if you should check with your doctor before you start. If you are over 69 years of age, and you are not used to being very active, check with your doctor.

Common sense is your best guide when you answer these questions. Please read the questions carefully and answer each one honestly: check YES or NO.

\begin{tabular}{|c|c|c|c|}
\hline YES & NO & & \\
\hline$\square$ & $\square$ & 1. & $\begin{array}{l}\text { Has your doctor ever said that you have a heart condition and that you should only do physical activity } \\
\text { recommended by a doctor? }\end{array}$ \\
\hline$\square$ & $\square$ & 2. & Do you feel pain in your chest when you do physical activity? \\
\hline$\square$ & $\square$ & 3. & In the past month, have you had chest pain when you were not doing physical activity? \\
\hline$\square$ & $\square$ & 4. & Do you lose your balance because of dizziness or do you ever lose consciousness? \\
\hline$\square$ & $\square$ & 5. & $\begin{array}{l}\text { Do you have a bone or joint problem (for example, back, knee or hip) that could be made worse by a } \\
\text { change in your physical activity? }\end{array}$ \\
\hline$\square$ & $\square$ & 6. & $\begin{array}{l}\text { Is your doctor currently prescribing drugs (for example, water pills) for your blood pressure or heart con- } \\
\text { dition? }\end{array}$ \\
\hline$\square$ & $\square$ & 7. & Do you know of any other reason why you should not do physical activity? \\
\hline & & & YES to one or more questions \\
\hline yo & & & $\begin{array}{l}\text { Talk with your doctor by phone or in person BEFORE you start becoming much more physically active or BEFORE you have a fitness appraisal. Tell } \\
\text { your doctor about the PAR-Q and which questions you answered YES. }\end{array}$ \\
\hline \multicolumn{2}{|c|}{ answered } & & $\begin{array}{l}\text { - You may be able to do any activity you want — as long as you start slowly and build up gradually. Or, you may need to restrict your activities to } \\
\text { those which are safe for you. Talk with your doctor about the kinds of activities you wish to participate in and follow his/her advice. } \\
\text { - Find out which community programs are safe and helpful for you. }\end{array}$ \\
\hline
\end{tabular}

\section{NO to all questions}

If you answered NO honestly to all PAR-Q questions, you can be reasonably sure that you can:

- start becoming much more physically active - begin slowly and build up gradually. This is the

safest and easiest way to go.

- take part in a fitness appraisal - this is an excellent way to determine your basic fitness so that you can plan the best way for you to live actively. It is also highly recommended that you have your blood pressure evaluated. If your reading is over 144/94, talk with your doctor before you start becoming much more physically active.

DELAY BECOMING MUCH MORE ACTIVE:

- if you are not feeling well because of a temporary illness such as a cold or a fever - wait until you feel better; or

- if you are or may be pregnant - talk to your doctor before you start becoming more active.

PLEASE NOTE: If your health changes so that you then answer YES to any of the above questions, tell your fitness or health professional. Ask whether you should change your physical activity plan.

Informed Use of the PAR-Q: The Canadian Society for Exercise Physiology, Health Canada, and their agents assume no liability for persons who undertake physical activity, and if in doubt after completing this questionnaire, consult your doctor prior to physical activity.

\section{No changes permitted. You are encouraged to photocopy the PAR-Q but only if you use the entire form.}

NOTE: If the PAR-Q is being given to a person before he or she participates in a physical activity program or a fitness appraisal, this section may be used for legal or administrative purposes.

"I have read, understood and completed this questionnaire. Any questions I had were answered to my full satisfaction."

NAME

SIGNATURE

SIGNATURE OF PARENT

or GUARDIAN (for participants under the age of majority)

DATE

WITNESS

Note: This physical activity clearance is valid for a maximum of 12 months from the date it is completed and becomes invalid if your condition changes so that you would answer YES to any of the seven questions. 
APPENDIX C:

RECRUITMENT FLYER

\section{Attention All Active Men's Illinois State Rugby Club Members:}

\section{You are invited to participate in a research study!}

Study: Changes in Anthropometric and Physiological Characteristics of Collegiate Male Rugby Union Players during a Competitive Season

The goal of the study is to identify any changes in participant's speed, agility, muscular power, mobility, body composition, and cardiovascular endurance levels throughout a competitive season.

11. Who can participate?: Those who are active members of the Illinois State Men's Rugby club, are between the ages of 18 and 25, and those who have no current injuries preventing them from participating in physical activity.

12. Where? Initial meeting and body composition testing will take place in the Exercise Physiology laboratory (McCormick Hall, room 177). Fitness testing will take place in the Instructional Gymnasium (McCormick Hall).

13. When? There will be three separate periods of data collection throughout the fall semester and season: pre-season (8/29-9/2), mid-season (10/3-10/7), and post-season (approximately 1-week after the last match of the season). For each data collection period, there will be two data collection sessions per participant (6 total sessions per person). A body composition assessment will take place throughout the week leading up to the fitness-testing session. The fitness testing session will take place on a Saturday or Sunday at the end of the week (for that data collection period).

14. What do I have to do? During body composition testing, you will undergo a skinfold and BODPOD assessment. Fitness tests include: Vertical jump, FMS active straight leg raise and shoulder mobility assessments, L-run agility drill, $20 \mathrm{~m}$ sprints, and a $20 \mathrm{~m}$ 
multistage shuttle run. Throughout the season, you will be asked to rate how hard you thought each training session and match was for you. 


\section{Rating of Perceived Exertion Borg RPE Scale}

\begin{tabular}{|c|c|c|}
\hline $\begin{array}{c}6 \\
7 \\
8 \\
9 \\
10 \\
11\end{array}$ & $\begin{array}{l}\text { Very, very light } \\
\text { Very light } \\
\text { Fairly light }\end{array}$ & $\begin{array}{l}\text { How you feel when lying in bed or } \\
\text { sitting in a chair relaxed. } \\
\text { Little or no effort. }\end{array}$ \\
\hline $\begin{array}{l}12 \\
13 \\
14 \\
15 \\
16\end{array}$ & $\begin{array}{l}\text { Somewhat hard } \\
\text { Hard }\end{array}$ & $\begin{array}{l}\text { Target range: How you should feel } \\
\text { with exercise or activity. }\end{array}$ \\
\hline $\begin{array}{l}17 \\
18 \\
19 \\
20\end{array}$ & $\begin{array}{l}\text { Very hard } \\
\text { Very, very hard } \\
\text { Maximum exertion }\end{array}$ & $\begin{array}{l}\text { How you felt with the hardest work } \\
\text { you have ever done. } \\
\text { Don't work this hard! }\end{array}$ \\
\hline
\end{tabular}

